\title{
Coupled climate response to Atlantic Multidecadal Variability in a multi-model multi-resolution ensemble
}

\author{
Daniel L. R. Hodson ${ }^{1}$ (1) - Pierre-Antoine Bretonnière ${ }^{2} \cdot$ Christophe Cassou $^{9} \cdot$ Paolo Davini $^{4} \cdot$ Nicholas P. Klingaman $^{1}$. \\ Katja Lohmann ${ }^{5}$. Jorge Lopez-Parages ${ }^{8} \cdot$ Marta Martín-Rey $^{3} \cdot$ Marie-Pierre Moine $^{9} \cdot$ Paul-Arthur Monerie $^{1}$. \\ Dian A. Putrasahan ${ }^{5}$. Christopher D. Roberts ${ }^{6}$. Jon Robson ${ }^{1} \cdot$ Yohan Ruprich-Robert ${ }^{2} \cdot$ Emilia Sanchez-Gomez $^{10}$. \\ Jon Seddon ${ }^{7} \cdot$ Retish Senan ${ }^{6}$
}

Received: 11 June 2021 / Accepted: 13 January 2022 / Published online: 7 February 2022

(c) The Author(s) 2022, corrected publication 2022

\begin{abstract}
North Atlantic sea surface temperatures (SSTs) underwent pronounced multidecadal variability during the twentieth and early twenty-first century. We examine the impacts of this Atlantic Multidecadal Variability (AMV), also referred to as the Atlantic Multidecadal Oscillation (AMO), on climate in an ensemble of five coupled climate models at both low and high spatial resolution. We use a SST nudging scheme specified by the Coupled Model Intercomparision Project's Decadal Climate Prediction Project Component C (CMIP6 DCPP-C) to impose a persistent positive/negative phase of the AMV in the North Atlantic in coupled model simulations; SSTs are free to evolve outside this region. The large-scale seasonal mean response to the positive AMV involves widespread warming over Eurasia and the Americas, with a pattern of cooling over the Pacific Ocean similar to the Pacific Decadal Oscillation (PDO), together with a northward displacement of the inter-tropical convergence zone (ITCZ). The accompanying changes in global atmospheric circulation lead to widespread changes in precipitation. We use Analysis of Variance (ANOVA) to demonstrate that this large-scale climate response is accompanied by significant differences between models in how they respond to the common AMV forcing, particularly in the tropics. These differences may arise from variations in North Atlantic air-sea heat fluxes between models despite a common North Atlantic SST forcing pattern. We cannot detect a widespread effect of increased model horizontal resolution in this climate response, with the exception of the ITCZ, which shifts further northwards in the positive phase of the AMV in the higher resolution configurations.
\end{abstract}

Keywords AMV $\cdot$ Atlantic multidecadal variability $\cdot$ AMO $\cdot$ Atlantic multidecadal oscillation $\cdot$ High resolution $\cdot$ Decadal variability

Daniel L. R. Hodson

d.1.r.hodson@reading.ac.uk

1 Department of Meteorology, University of Reading, Earley Gate, PO Box 243, Reading RG6 6BB, UK

2 Barcelona Supercomputing Center, Carrer de Jordi Girona, 29-31, 08034 Barcelona, Spain

3 Departamento de Física de la Tierra y Astrofísica, Facultad de Ciencias Físicas, Universidad Complutense de Madrid, 28040 Madrid, Spain

4 Consiglio Nazionale delle RicercheInstituto di Scienze dell'Atmosfera e del Clima (CNR-ISAC), 10133 Turin, Italy
5 Max Planck Institute for Meteorology, Bundesstrasse 53, 20146 Hamburg, Germany

6 ECMWF, Reading, UK

7 Met Office, FitzRoy Road, Exeter, EX1 3PB Devon, UK

8 CECI, Université de Toulouse, CERFACS/CNRS, Toulouse, France

9 CERFACS Toulouse, Toulouse, France

10 CERFACS/CECI, Toulouse, France 


\section{Introduction}

Over the twentieth century, Sea Surface Temperatures (SSTs) in the North Atlantic underwent periods of warming and cooling. These SST variations are now commonly referred to as the Atlantic Multidecadal Variability (AMV). Earlier studies use the term Atlantic Multidecadal Oscillation (AMO: Kerr 2000), but doubts about the oscillatory nature, given the short observational record led to the revised, more general name.

Observational studies suggest that the AMV has multiple impacts on climate (Gastineau and Frankignoul 2014; O'Reilly et al. 2017; Peings and Magnusdottir 2014; Nigam et al. 2018), including the following: changes in rainfall on both sides of Atlantic (Folland et al. 1986; Hoerling et al. 2006; Zhang and Delworth 2006; Uvo et al. 1998; Folland et al. 2001; Zhou and Lau 2001; Knight et al. 2006), warming and drying over North America (Sutton and Hodson 2005, 2007; Hodson et al. 2009), changes in European summer climate (Sutton and Dong 2012), hurricane formation (Shapiro and Goldenberg 1998; Enfield et al. 2001; Goldenberg et al. 2001) and Atlantic winter atmospheric blocking (Kwon et al. 2020). Modelling studies also suggest the AMV drives changes outside the Atlantic region; the Asian and Indian monsoon (Zhang and Delworth 2006, 2005), Siberian rainfall (Sun et al. 2015), Antarctic sea ice (Li et al. 2014) and modulation of the ENSO (Dong and Sutton 2007). A number of these links between the AMV and impacts have also been seen in historical and pre-industrial coupled climate model integrations (Ting et al. 2011; Lyu and $\mathrm{Yu}$ 2017).

The ultimate driver of the AMV remains a matter of debate. Patterns similar to the observed AMV (Fig. 1) are associated with multidecadal variations in the Atlantic Meridional Overturning Circulation (AMOC) in coupled climate models (Delworth et al. 1993; Vellinga and Wood 2002; Zhang and Delworth 2005; Dong and Sutton 2007; Knight et al. 2006; Hodson and Sutton 2012; Ruprich-Robert and Cassou 2015) suggesting that historical variations in the AMOC may have played a role in the observed AMV. However, the 20th century also saw considerable variation in natural and anthropogenic forcings (Hodson et al. 2014); anthropogenic aerosols rose and then declined over the region, volcanic activity reduced mid-century (Sato et al. 1993) whilst total solar irradiance (TSI) underwent considerable variability in the solar cycle around an upward trend (Lean 2018). The historical variations of anthropogenic aerosols in coupled climate models modulate Atlantic SST and reproduce the observed phasing and magnitude of the AMV (Booth et al. 2012; Watanabe and Tatebe 2019; Undorf et al. 2018). Others studies suggest that volcanic stratospheric aerosols played a key role (Otterå et al. 2010;

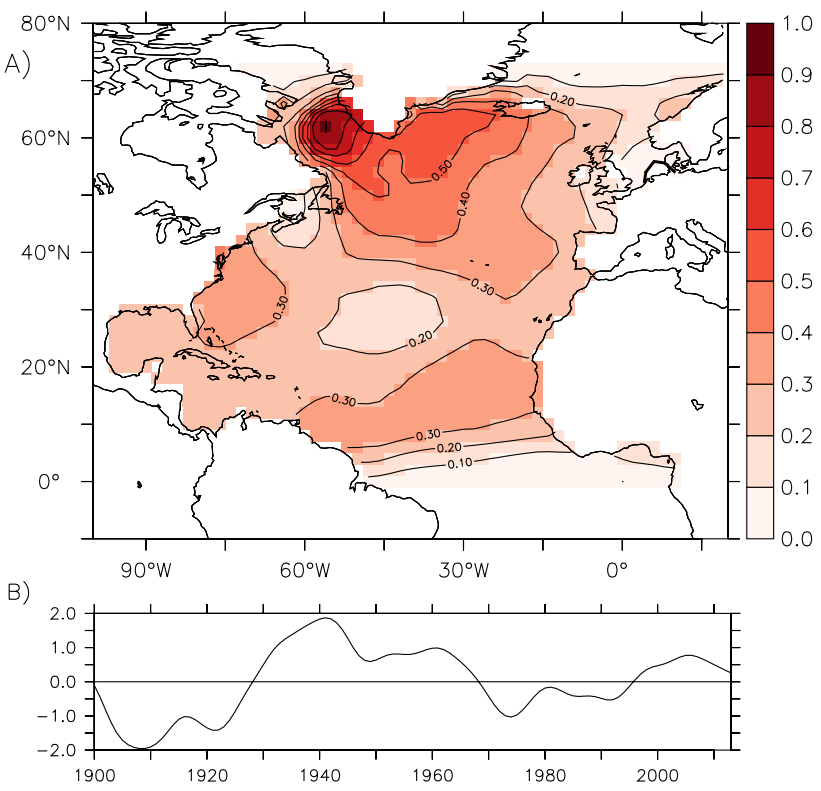

Fig. 1 A) $2 * A M V^{+}$anomaly pattern used in model experiments. The AMV pattern is derived from observed Sea Surface Temperatures (SSTs), as described by the CMIP6 DCPP-C protocol (Boer et al. 2016) https://www.wcrp-climate.org/wgsip/documents/Tech-Note1.pdf. Here we double this pattern-see Sect. 2.3 for more details. Units: K (per standard deviation). Contours are 0.2K. B) Associated AMV timeseries (low-passed and standardized)

Birkel et al. 2018), possibly by exciting multidecadal coupled modes of variability in the subpolar gyre and Labrador Sea (Swingedouw et al. 2015). The possibility also remains that the AMV may arise simply as a consequence of the ocean mixed layer integrating high-frequency atmospheric noise (Clement et al. 2015).

Whatever the ultimate origin of the AMV, the question remains: what is the climate response to the AMV? Previous studies have demonstrated significant global climate impacts using atmosphere-only models forced by AMV patterns (Sutton and Hodson 2005, 2007; Hodson et al. 2009; Davini et al. 2015; Vigaud et al. 2018; Omrani et al. 2014, 2016; Peings and Magnusdottir 2014; Mohino et al. 2011; Elsbury et al. 2019). However, such experiments do not capture the response of the ocean to this AMV forcing, and any consequent feedback on global climate. Early AMV studies using coupled atmosphere-ocean models (e.g. Zhang and Delworth 2006; Dong et al. 2006) suggested that such coupled feedbacks might be significant. Recent studies have begun to examine these feedbacks in more detail by imposing AMV forcing patterns in coupled atmosphere-ocean climate models (Kucharski et al. 2016, 2016b; Ruprich-Robert et al. 2017, 2018; Levine -et al. 2018; Qasmi et al. 2017).

These coupled model studies find widespread global impacts beyond those found in the atmosphere-only studies and hence warrant further examination. A coordinated 
coupled AMV experiment was therefore proposed to assess the robustness of these responses across models and was subsequently included in the Decadal Climate Prediction Project MIP (DCPP-C Boer et al. 2016), as part of CMIP6. However, one key question that arises, is how dependent are these responses on model spatial resolution? The EU Horizon 2020 PRIMAVERA project (https://www.primaverah2020.eu/) aimed to assess the impact of increased model resolution on a wide range of climate processes. As part of PRIMAVERA we examined the global climate impact of the AMV in five coupled climate-models in both low and high spatial resolution configurations. This allows us to assess how the modelled climate impact of the AMV is dependent on model design and model horizontal resolution.

In this paper we focus on these three key questions:

- What is the global coupled climate response to the AMV across these five models?

- How consistent is this response across the models?

- Does increasing model resolution alter this response?

This paper is set out as follows. Section 2 outlines the climate models, data and methodology used in the AMV experiments. Section 3 outlines the ANOVA technique (we provide a more detailed explanation in Appendix A). Section 4 presents the results of the analysis of these experiments. We then discuss these results in Sect. 5 and present our conclusions in Sect. 6. Additional analysis supporting this analysis can be found in the Supplementary Information.

\section{Models, regridding, experimental design, and data}

\subsection{Models}

We employed five coupled climate models in this study (CNRM-CM6-1, EC-Earth, ECMWF-IFS, MetUM-GOML2 and MPI-ESM1.2). The AMV experiments were performed at two groups of horizontal resolutions for each atmosphere model: low resolution (LR: $250-100 \mathrm{~km}$ ) and high resolution (HR 100-50 km) for each model (summarized in Table 1). Brief descriptions of the five climate models and their formulations are given below.

\subsubsection{CNRM-CM6-1}

CNRM-CM6-1 is coupled climate model consisting of the ARPEGE-Climat (Déqué et al. 1994) atmospheric model coupled to the NEMO v3.6 ocean model (Madec et al. 2017) via the OASIS3-MCT coupler (Craig et al. 2017). The model also includes a land surface scheme (ISBA-Noilhan and Planton 1989), the GELATO v6 (Salas Mélia 2002) sea ice
Table 2 AMV experiments-number of ensemble members for the $2 \mathrm{AMV}+(2 \mathrm{AMV}-)$ experiment for each model and resolution. For each model, each realization was integrated for 10 years. We consider each year of a given realization to be independent (see SI section 9), hence combine realizations*years to give the total available number of ensemble members

\begin{tabular}{lll}
\hline Model & Low resolution & High resolution \\
\hline CNRM-CM6-1 & 250 & 100 \\
EC-Earth & 250 & 170 \\
ECMWF-IFS & 300 & 150 \\
MetUM-GOML2 & 150 & 150 \\
MPIESM1.2 & 100 & 100 \\
\hline
\end{tabular}

model, the SURFEX (Masson et al. 2013) externalized surface interface model, and the CTRIP (Decharme et al. 2019) river routing scheme. For full details see Voldoire et al. (2019). CNRM-CM6-1-LR uses a spectral model atmosphere with 91 vertical levels and a horizontal truncation of T127, resulting in a resolution at the equator of about $1.4^{\circ}$. The ocean has 75 vertical levels and a horizontal resolution of about $1^{\circ}$, reducing to $1 / 3^{\circ}$ in the tropics. CNRM-CM61 -HR uses a spectral model with 91 vertical levels and a horizontal truncation of $\mathrm{T} 359$, resulting in a resolution at the equator of about $0.5^{\circ}$. The ocean has 75 vertical levels and a horizontal resolution of about $0.25^{\circ}$.

\subsubsection{EC-Earth}

EC-Earth3P and EC-Earth3P-HR (Haarsma et al. 2020) are coupled climate models consisting of an atmospheric component based on the IFS (cycle 36r4 of the Integrated Forecast System (IFS) atmosphere-land-wave model of the European Centre for Medium Range Weather Forecasts (ECMWF)) coupled to NEMO (v3.6 Madec et al. 2017). The H-TESSEL model is used for the land surface (Balsamo et al. 2009) and is an integral part of IFS: for more details see Hazeleger and Bintanja (2012). The atmosphere and ocean/sea ice parts are coupled through the OASIS (Ocean, Atmosphere, Sea Ice, Soil) coupler (Valcke 2013). The ice model, embedded in NEMO, is the Louvain la Neuve sea ice model version 3 (LIM3, Vancoppenolle et al. 2012), which is a dynamic-thermodynamic sea ice model with 5 thickness categories. EC-Earth3P uses a reduced Gaussian-grid with 91 vertical levels and a T255 horizontal truncation/ N128 grid resolution $(\sim 100 \mathrm{~km})$ for the IFS atmosphere. The NEMO ocean has 75 vertical levels and a horizontal resolution of about $1^{\circ}$, reducing to $1 / 3^{\circ}$ in the tropics. The higher resolution EC-Earth3P-HR uses a T511 horizontal truncation/N256 grid resolution ( $\sim 50 \mathrm{~km})$ IFS atmosphere, together with a $0.25^{\circ} \mathrm{NEMO}$ ocean and 75 vertical levels. 


\subsubsection{ECMWF-IFS}

ECMWF-IFS is a global Earth system model that includes dynamic representations of the atmosphere, sea ice, ocean, land surface, and ocean waves. A detailed description of the ECMWF-IFS-HR and ECMWF-IFS-LR configurations used in this study, including scientific assessment of the coupled model performance, is provided in Roberts et al. (2018). ECMWF-IFS is based on the IFS atmosphere-landwave model (cycle 43r1) coupled to NEMO (v3.4 Madec et al. 2017) and the Louvain-la-Neuve Sea Ice Model (LIM2; Bouillon et al. 2009; Fichefet and Maqueda 1997). ECMWF-IFS-LR uses a reduced Gaussian octahedral grid (Tco199 $\sim 100 \mathrm{~km}$ ) in the atmosphere and NEMO ORCA1 grid $(\sim 100 \mathrm{~km})$ for ocean-sea ice. ECMWF-IFS-HR uses (Tco399 50 km) in the atmosphere and NEMO ORCA025 grid $(\sim 25 \mathrm{~km})$ for ocean-sea ice. One of the significant differences between these configurations is the use of the Gent and Mcwilliams (1990) parameterization for the effect of mesoscale eddies with the ORCA1 grid, which is disabled when using the ORCA025 grid. Both ocean configurations use the same vertical discretization, which consists of 75 z-levels and partial cells at the ocean floor.

\subsubsection{MetUM-GOML2}

MetUM-GOML2 is an ocean mixed-layer coupled configuration of the Met Office Unified Model (MetUM-GOML2; Hirons et al. 2015); combining the atmosphere component from HadGEM3 (GA6.0; Walters et al. 2017) coupled to a Multi-Column K Profile (MC-KPP) mixed layer Ocean model (Hirons et al. 2015) via the Ocean Atmosphere Sea Ice Soil (OASIS) coupler (Valcke 2013) ). For full details of MetUM-GOML2 see Hirons et al. (2015). The atmosphere and ocean have a horizontal resolution of either $1.25 \times 1.87^{\circ}$ ( 250 km, N96-LR) or $0.833 \times 0.55^{\circ}(\sim 100 \mathrm{~km}, \mathrm{~N} 216-$ HR). The Atmosphere has 85 vertical levels whilst the ocean mixed-layer component extends to $1 \mathrm{~km}$ depth with 100 vertical levels. Sea ice fraction is prescribed from 1976-2005 mean climatology, as is Sea Surface Temperature in regions that are not ice-free all year. Although there is vertical ocean mixing, there is no horizontal advection or mixing in the model; these terms are replaced by seasonally-varying $3 \mathrm{~d}$ temperature and salinity flux corrections, diagnosed from seasonal climatologies. Consequently, MetUM-GOML2 has small sea surface temperature biases and small model drifts (Hirons et al. 2015). In this paper, a 1976-2005 mean ocean temperature and salinity reference climatology is used, derived from the Met Office ocean analysis (Smith and Murphy 2007). Anthropogenic greenhouse gases concentration, aerosol emissions, volcanic activity are imposed and kept constant to their mean value of the period 1976-2005.

\subsubsection{MPI-ESM-1-2}

MPI-ESM (version 1.2.01), consisting of the atmosphere component ECHAM6.3 (Stevens et al. 2013) including the land-surface scheme JSBACH, the combined ocean and sea ice component MPIOM1.6.3 (Jungclaus et al. 2013) including the ocean biogeochemical component HAMOCC. Ocean and atmosphere are coupled through the OASIS3 coupler (Valcke 2013) with a coupling frequency of one hour. The atmosphere component applies a spectral grid at truncation T127 (about $1^{\circ}, \mathrm{LR}$ ) or T255 (about $0.5^{\circ}, \mathrm{HR}$ ) and 95 hybrid levels. The ocean component applies a tripolar grid (two northern poles) with a nominal resolution of $0.4^{\circ}$ and 40 unevenly spaced z-levels. The first 20 levels are distributed over the upper $700 \mathrm{~m}$ of the water column. A partial grid cell formulation is used to better represent the bottom topography.

\subsection{Regridding}

Each model and resolution (Table 1) uses a different horizontal model grid. In order to compare a model variable between models and resolutions on a grid-point basis, the variables are regridded to a common grid using bilinear interpolation. For all variables we regrid to a $1^{\circ} \times 1^{\circ}$ longitude latitude grid. This will potentially result in the loss of some small-scale differences between high and low resolutions, but our primary focus in this study is the impact of increased resolution on the large-scale climate response to the AMV, rather than such smaller scale impacts.

\subsection{Experimental design}

The goal of this study is to assess the global impact of the AMV using coupled climate models. Previous atmosphereonly studies (e.g. Sutton and Hodson 2005; Hodson et al. 2009; Davini et al. 2015; Vigaud et al. 2018) used AMV SST anomalies (derived from observations) to drive atmosphere models. In a coupled ocean-atmosphere model, a balance must be preserved between maintaining the AMV SST pattern (on a background SST climatology), and permitting the ocean to respond to anomalous fluxes from the atmosphere. To achieve this, we followed a modified form of the experimental design proposed for the CMIP6 DCPP-C AMV experiments. Full details of this design are given in Boer et al. (2016). We briefly outline this experimental design and the necessary modifications that were required for the experiments presented here.

The AMV forcing pattern used in these experiments is shown in Fig. 1. This pattern was generated from observed SSTs (ERSST4 Huang et al. 2015) after removing an estimate of the global forced trend (from CMIP5, by regression). (Full details of this method is given in https://www. 
wcrp-climate.org/wgsip/documents/Tech-Note-1.pdf). This AMV pattern is similar to those diagnosed in other studies; the horseshoe structure with higher values in the subpolar gyre (SPG) (e.g. Sutton and Hodson 2005; Deser et al. 2010; Buckley and Marshall 2016). Figure 1 does display a more prominent small maximum in the Labrador Sea than these other studies, this may arise due to the different methods used to remove the global mean SST trend.

For each model experiment, SSTs within the North Atlantic (using a predefined mask) are nudged towards the target SST field constructed from an SST climatology plus or minus the $2 *$ AMV spatial pattern in Fig. 1: $S S T_{\text {target }}=$ Climatology $\pm 2 * A M V$. Climatology is a model climatology derived from a control run (or observations, in the case of MetUM-GOML2-see section 2.1.4). SST nudging is achieved through an additional surface heat flux term hfcorr, defined as:

hfcorr $=-40\left(S S T_{\text {model }}-S S T_{\text {target }}\right)$

The coefficient of $-40\left(\mathrm{~W} / \mathrm{m}^{2} / \mathrm{K}\right)$ was chosen based on a range of sensitivity studies (for details see http://www.wcrpclimate.org/wgsip/documents/Tech-Note-2.pdf).

Each model is then integrated multiple times, each starting from atmosphere and ocean initial conditions taken from different points in a control integration. Each realization is integrated for a maximum of 10 years, to prevent $h f c o r r$ from generating significant anomalies in the unconstrained subsurface ocean, which could significantly impact on deep ocean circulations and hence overwhelm the AMV forced signal. The resulting difference between the $2 A M V^{+}$and $2 A M V^{-}$experiments can then be used to assess the impact of AMV forcing on global climate. We assume that each year in a realization is statistically independent, hence we consider each year to be an ensemble member. (We examine this assumption further in SI section 9.)

One of the goals of this study (and a focus of the PRIMAVERA project), is to assess the impact of increased model resolution. Integrating a climate model at a higher resolution requires extra computational resources. In order to meet this goal within the available computing resources, we used a modified form of the DCPP-C AMV experimental design by doubling the originally specified AMV forcing pattern (hence $2 A M V$ ). This enhanced forcing reduces the number of realizations required to produce a detectable response. For consistency, we use this enhanced forcing $(2 A M V)$ for both LR and HR experiments. The DCPP-C protocol defined the use of a pre-industrial control climatology as the background climatology. However, none of the models had (or were likely to have) high resolution pre-industrial control integrations performed, as required by the DCPP-C protocol. Instead, each model (at both resolutions) used a 1950s constant-forcing control that had already been produced as part of the PRIMAVERA project. One model (MetUMGOML2), used a later climatology (1976-2014), derived from observations, due to the nature of the model design (see Sect. 2.1.4).

\subsection{Data availability}

All the model data used in this study, together with the code used to analyse and plot the results are available to download via https://doi.org/10.5281/zenodo.5884227. The full experimental dataset is available at https://prima-dm1.jasmin.ac. uk/ and at the ESGF https://esgf-index1.ceda.ac.uk/search/ esgf-ceda/ (search for primwp5 or $d c p p$-for MPI-ESM). Please contact the authors for further help accessing these datasets.

\subsubsection{Observations}

For observational comparisons we use the HadCRUT4 (https://www.metoffice.gov.uk/hadobs/hadcrut4/ Morice et al. 2012) surface air temperature (tas) dataset and the HadSLP2 (https://www.metoffice.gov.uk/hadobs/hadslp2/ Allan and Ansell 2006) mean sea level pressure (psl) dataset.

\section{ANOVA}

In the following section we use Analysis of Variance (ANOVA) to examine the global climate response to the AMV and how this response varies across the models and between resolutions. ANOVA is a common statistical technique that simultaneously examines the influence of a set of predictors or factors on a dependent variable. It is closely related to multiple linear regression, but can also be used with categorical factors, such as choice of climate model. It is also a generalization of the two-sample $t$ test (see the appendix (A)) and is better at detecting significant impacts from multiple factors than the application of multiple $t$ tests, as it simultaneously accounts for all sources of variance.

ANOVA has widespread use in many fields, but has only had limited application to climate science to date (e.g. Hodson and Sutton 2008; Yip et al. 2011; Christensen and Kjellström 2020). We provide a brief outline of the basis for ANOVA and its relation to $t$-tests in the Appendix (A). For a more detailed explanation and the application of ANOVA to climate models see Storch and Zwiers (1999), Zwiers (1996), Hodson and Sutton (2008), Yip et al. (2011) or Wilks (2019).

Much like linear regression, ANOVA begins by proposing a statistical model, consisting of a predictor, or combination of predictors, to explain the variance in a given variable. For example, a model variable $X_{e j}$ (e.g. mean sea level 
pressure-where $e$ is the experiment, and $j$ is the ensemble member) can be represented by:

$X_{e j}=\mu+\alpha_{e}+\epsilon_{e j}$.

Here $\mu$ is the mean (over both $e$ and $j$ ), and $\epsilon_{e j}$ is a residual noise term, which we assume is independently and normally distributed with a variance $\sigma_{\epsilon}^{2}$ (i.e. $\epsilon_{e j} \sim N\left(0, \sigma_{\epsilon}^{2}\right)$ ). Hence a predictor $\left(\alpha_{e}\right)$ can then be assessed to see if it explains a significant fraction of the variance of variable $X_{e j}$, with respect to the residual noise term $\epsilon_{e j}$. The similarity with linear regression is clear (e.g. $y=c+m x+\epsilon$ ).

In this study our dataset $X_{e m r j}$, consists of two experiments $\left(e: 2 A M V^{+}, 2 A M V^{-}\right)$, five models $(m)$, two resolutions ( $r$ : LR, HR), and multiple ensemble members $(j)$. We can propose the following statistical model for this dataset combining these predictors and their interactions:

$X_{e m r j}=\mu+\alpha_{e}+\beta_{m}+\gamma_{r}+A_{e m}+G_{e r}+Z_{m r}+W_{e m r}+\epsilon_{e m r j}$

Here $\alpha_{e}$ represents the variation in $X_{e m r j}$ due to the experiments $\left(e: 2 A M V^{+}, 2 A M V^{-}\right)$averaged across all models $(m)$, resolutions $(r)$ and ensemble members $(j) . A_{e m}$ is an interaction term, and represents the variation in $X_{e m r j}$ due to both the experiments $(e)$ and models $(m)$. In this way we can examine the impact of the AMV $\left(\alpha_{e}\right)$, and also both how this impact varies across the models $\left(m: A_{e m}\right)$, and changes with model resolution $\left(r: G_{e r}\right)$. The remaining terms describe other aspects of the dataset, for example, $\beta_{m}$ describes the spread of climatologies between models $(m)$ (see the appendix (A)). We do not consider these further terms in the remainder of this study, but focus on the impact of the experiment $\left(\alpha_{e}\right)$, the impact of the choice of model on the experiment $\left(A_{e m}\right)$, and the impact of the choice of resolution on the experiment $\left(G_{e r}\right)$.

\section{Results}

We now present the results of the AMV experiments. Rather than presenting the results for each model at each resolution, we use the above ANOVA analysis to examine the climate response to the AMV for each season and the influence of resolution and model on this response. We begin by examining the multi-model, multi-resolution mean responses $\left(\alpha_{e}\right)$ for each season. We then examine where the models significantly differ in their AMV response $\left(A_{e m}\right)$. Finally we examine whether the AMV response changes with increased resolution $\left(G_{e r}\right)$. To ensure the analysis is not biased towards any single model, we use the same number of ensemble members for each experiment, model and resolution in the analysis -100 (10 realizations $\times 10$ years) members for each season ( 90 for DJF, as most models start on the 1st January, only 9 consecutive winters are available), e.g. a total of 1000 (DJF: 900) across models, resolution and members for each experiment. When a model has more that 100 (DJF: 90) ensemble members (see Table 2), we randomly subsample 100 (DJF: 90) from the full ensemble. The analysis results are mostly the same for different random subsamples (we examine this further in the Supplementary Information: SI Sect. 1-Figures S1-S9). There is some sensitivity to subsampling when examining the impact of resolution, which we discuss below.

We also attempt to assess the field significance of these results (Storch and Zwiers 1999; Livezey and Chen 1983) by counting all grid points where a result is significant $(p<0.05)$ and dividing this by the total number of gridpoints. This ratio is shown in each panel of the subsequent spatial field figures. For data drawn from the same random distribution we would expect this fraction to be 0.05 for a gridpoint threshold of $p<0.05$. In the absence of covariances between neighbouring gridpoints, we could therefore classify any field where this fraction is $>0.05$ to be field significant, hence reject the null hypothesis of it occurring purely by chance. In practice, there will be such covariances, and this will lead to an elevated threshold for field significance (i.e. greater than 0.05 ). There is no obvious objective method of assessing the resulting reduction of the degrees of freedom in this set of experiments, therefore we use this threshold as a guide; if a result falls below the field significance threshold, we can reject it, if it far exceeds the threshold, we can accept it. We should be more cautious, however if a result only just exceeds the threshold.

\subsection{Multi-model multi-resolution mean response}

We first examine the seasonal mean climate response to the AMV for three key climate variables, surface air temperature (tas), precipitation (pr) and mean sea-level pressure (psl). For each variable, we average over models, resolutions and ensemble members and compute the seasonal mean difference between the two experiments $\left(2 * A M V^{+}-2 * A M V^{-}\right)$. These differences between the experiments considered are significant where $\alpha_{e}$ is significant in the ANOVA ( $p<0.05$, Eq. (3)). The following results are robust to subsampling (see SI section 1.1—Figures S1-S3).

\subsubsection{Surface air temperature}

Figure 2 shows the seasonal mean surface air temperature response to the AMV $\left(\alpha_{e}, 2 * A M V^{+}-2 * A M V^{-}\right)$. The imposed time-invariant AMV SST pattern (Fig. 1a) is generally well maintained in the North Atlantic throughout the year (Fig. 2), although there is some seasonal variation. (A very similar pattern is seen in the model SSTs-SI section 2-Figure S10). The northern 
sub-polar maximum is weakest in spring (MAM), perhaps due to deeper mixed layer depths that occur during late winter and early spring (Montégut et al. 2004); the larger heat capacity of the deeper mixed ocean column leading to a longer adjustment timescale for a given nudging heat flux (Eq. 1).

The AMV drives a downstream warming of surface air temperatures to the east of the Atlantic basin; much of Eurasia and northern Africa is warmer throughout the year. Over Europe, this warming is largely confined to the western and southern edges. Central Europe shows a much weaker warming, particularly in summer (JJA, Fig. 2c). This weaker warming is not what would be expected from a simple advection by the mean flow of the warm North Atlantic anomalies (e.g. $\bar{V} T^{\prime}$ ), and may arise due to colder polar air being advected into the region by the atmospheric circulation response to the AMV (e.g. $V^{\prime} \bar{T}$ (Fig. 3c)). The balance between such dynamic $\left(V^{\prime} \bar{T}\right)$ and thermodynamic $\left(\bar{V} T^{\prime}\right)$ contributions to the climate response to the AMV have been examined in both observations (O'Reilly et al. 2017) and model studies (Qasmi et al. 2017) using analog reconstructions to separate the two processes. O'Reilly et al. (2017) demonstrates that the circulation response to the AMV acts to reinforce the warming of summer temperatures in Europe in observations. This difference may arise due to multiple confounders present in the observations with respect to the AMV forcing experiments, or climate model deficiencies, but highlights the potential regional sensitivities of the response to the detailed pattern of the circulation response.

North and South America show large regions of warming throughout the year-peaking in summer (JJA) in the United States (Fig. 2c), consistent with previous studies (e.g. Sutton and Hodson 2005; Ruprich-Robert et al. 2017). Over North America, the summer warming may arise as a response to the increased descent (and hence reduced cloud cover and increased insolation) in the atmosphere associated with the Gill-type response in mean sea level pressure (pslFig. 3-see Sect. 4.1.3), as described by Ruprich-Robert et al. (2018). In South America, the warming peaks in spring (SON, Fig. 2d). Warming of northeast Asia peaks in autumn
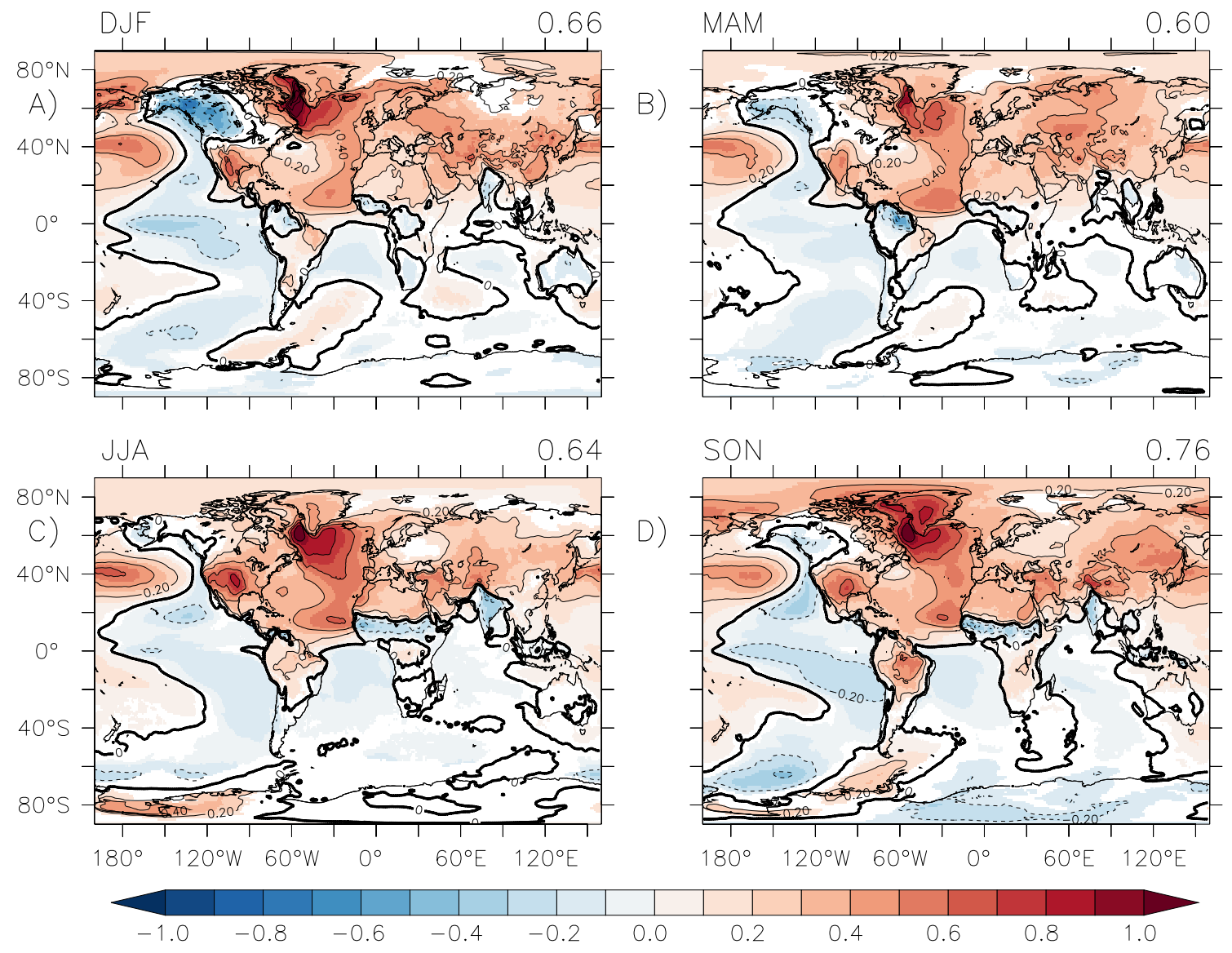

Fig. 2 Seasonal Surface Air Temperature (tas) mean (averaged over all models, resolutions and ensemble members) AMV response $\left(2 A M V^{+}-2 A M V^{-}\right)$. A) Winter (Dec-Jan)). B) Spring (Mar-May). C) Summer (Jun-Aug). D) Autumn (Sep-Nov). Regions where the differ- ence is significant (see Sect. 3, Eq. 3: $\alpha_{e}, p<0.05$ ) are shaded. Units: $\mathrm{K}$. Contours are $0.2 \mathrm{~K}$. Top right of each panel: fraction of the total number of gridpoints that are significant $(p<0.05)$ 

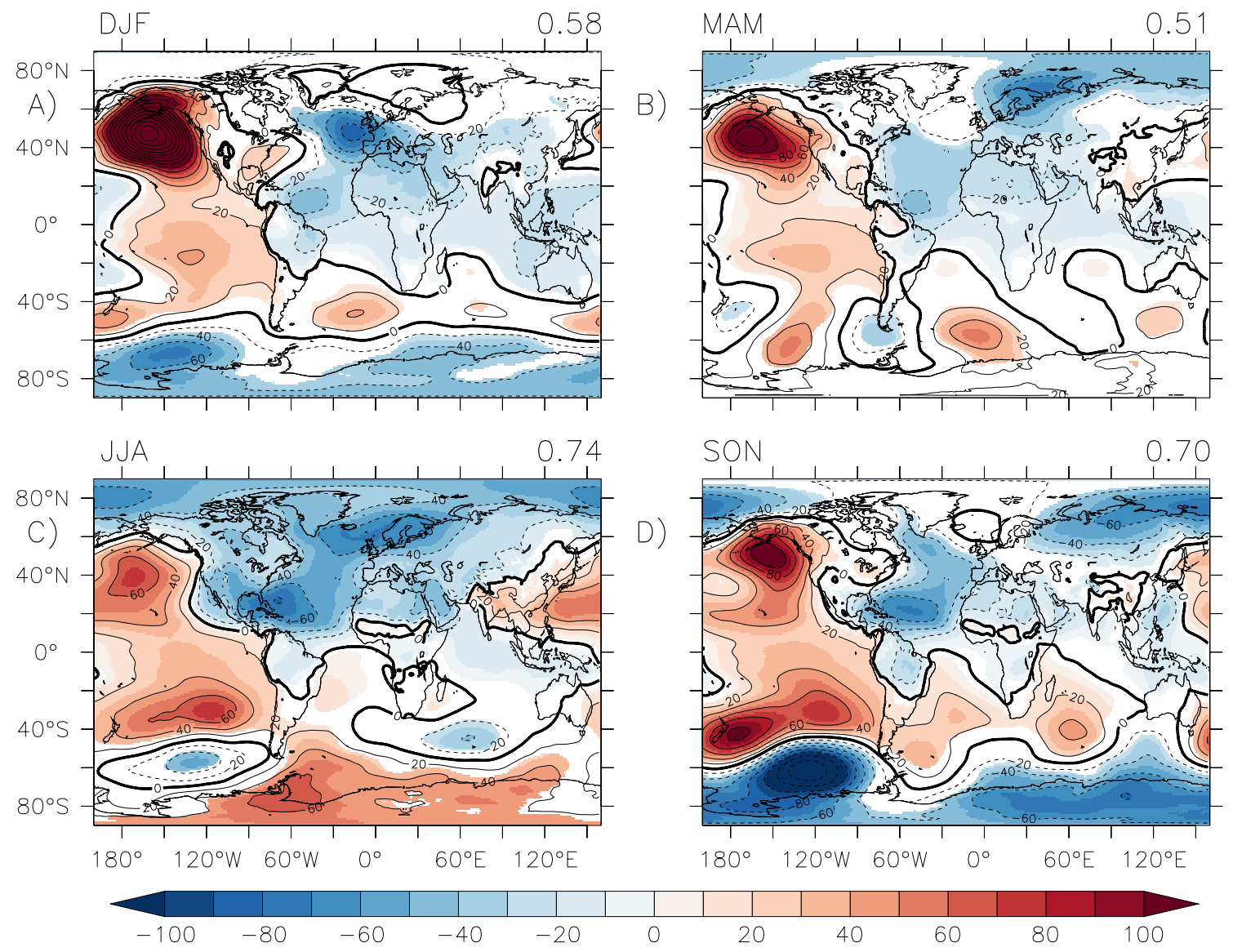

Fig. 3 As Fig. 2, but for mean sea level pressure (psl). Units: Pa. Contours show the mean sea level pressure difference for all regions-contour interval: $20 \mathrm{~Pa}$

(SON) and may be driven by the changes in atmospheric circulation as described in Monerie et al. (2020).

Whilst most impacts over land are warmings, the AMV drives a cooling over some land regions: northern South America, western Canada and Alaska during winter and spring (Fig. 2 a, b) and India, northern sub-Saharan Africa during summer and autumn (Fig. 2 c, d). These coolings may be due to reduced net surface shortwave radiation from increased cloud cover associated with the enhanced precipitation (northern South America, India, northern sub-Saharan Africa-see Fig. 4 and Sects. 4.1.2 and 5) or strong changes in circulation (western Canada and Alaska-see Fig. 3 and Sect. 4.1.3).

The AMV also drives significant surface air temperature changes over the oceans beyond the North Atlantic (the same pattern is seen in SSTs (tos) SI section 2-Figure S10). The Aleutian low region in the north Pacific is warm throughout the year and the eastern and central Pacific experiences a widespread cooling, peaking in winter (DJF, Fig. 2a) and autumn (SON, Fig. 2d). This pattern of warm and cool anomalies is close to the Pacific Decadal Oscillation (PDO: Zhang and Delworth 2015) and is a common Pacific response in Atlantic-forced coupled models (Ruprich-Robert et al. 2017; McGregor et al. 2014; Kucharski et al. 2011; Li et al. 2016); we discuss this further in Sect. 4.3.

\subsubsection{Precipitation}

The global precipitation response (Fig. 4) is dominated by dipolar anomalies within the tropics, which imply a northward shift in the Inter Tropical Convergence Zone (ITCZ). In the North Atlantic, the ITCZ undergoes a northward shift in all seasons. This is likely due to the enhanced heating within the northern hemisphere modifying the northward global energy transports, a modified Hadley circulation, and a consequent northward displacement of the ITCZ (see Kang et al. 2008).

This ITCZ displacement response is accompanied by an enhanced African monsoon in summer (JJA, Fig. 4c), increased precipitation in northern South America in winter (DJF, Fig. 4a) and spring (MAM, Fig. 4b), followed by reduced precipitation throughout South America during the remainder of the year. 

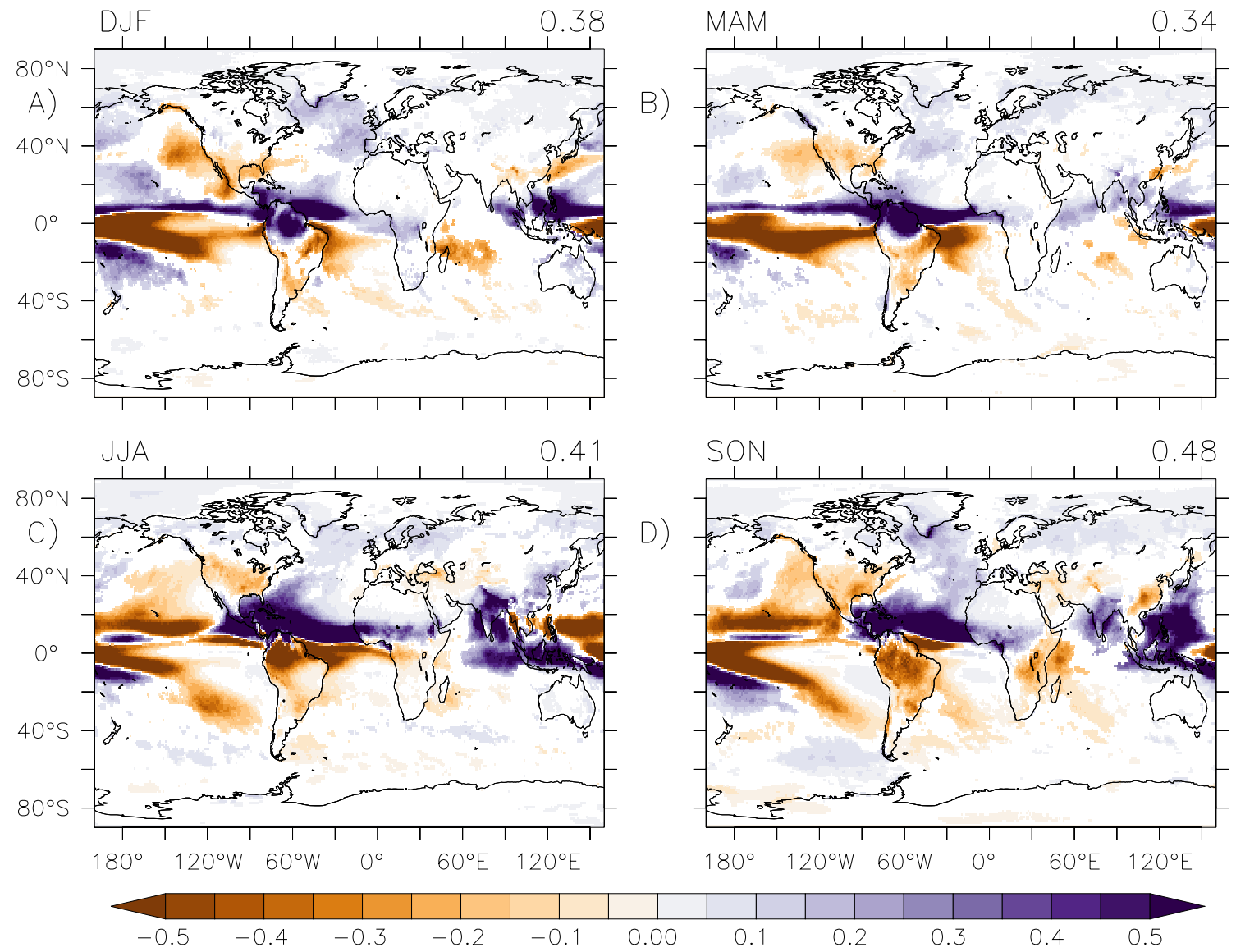

Fig. 4 As Fig. 2, but for precipitation (pr). Units: mm/day

Precipitation is reduced over North America in all seasons, with summer (JJA, Fig. 4c) and autumn (SON, Fig. 4d) showing the most widespread reductions.

Such reductions may be driven by enhanced subsidence over the region associated with the circulation response over North America (Fig. 3) as noted above, and described by Ruprich-Robert et al. (2018). There are small increases in precipitation over Europe (Fig. 4), mainly over southern and western Europe, but peaking over northern Europe and Scandinavia in summer (JJA). These increases may be the result of the circulation response driving a northward displacement of the Atlantic jet (Figs. 3 and SI section 3-Figure S12).

The AMV drives an increased Indian monsoon (JJA, SON; Fig. 4c, d), possibly driven by the increased landsea temperature contrast between the Indian Ocean and the Tibetan Plateau (Zhang et al. 2004) (Fig. 2), together with an increased rainfall over eastern China in summer (JJA, Fig. 4c) followed by a reduction in autumn (SON, Fig. 4 d). The impacts over eastern China are consistent with the circulation response (JJA, Fig. 3c) modifying seasonal rainfall patterns and are consistent with an earlier studies using a single model (Monerie et al. 2019, 2020).
There are widespread precipitation anomalies across the Pacific Ocean. These are predominantly characterized as a northwards shift of the ITCZ and a southward shift of the South Pacific convergence zone (SPCZ). The reduced precipitation over the South and tropical Pacific is likely related to the cooler surface temperatures over the region (Fig. 2)-most likely this is a response to increased subsidence over the Pacific (Monerie et al. 2020). We discuss the link between this displacement of the ITCZ and the Pacific cooling further in section 4.3. These widespread monsoonal changes in rainfall are examined further in detail using a precipitation budget analysis (for a single model in the ensemble) by Monerie et al. (2019).

\subsubsection{Mean sea level pressure}

Figure 3 shows the widespread global impact of the AMV on global circulation. The large scale response is a low pressure anomaly over much of the AMV forcing region in the North Atlantic and high pressure anomalies over large parts 

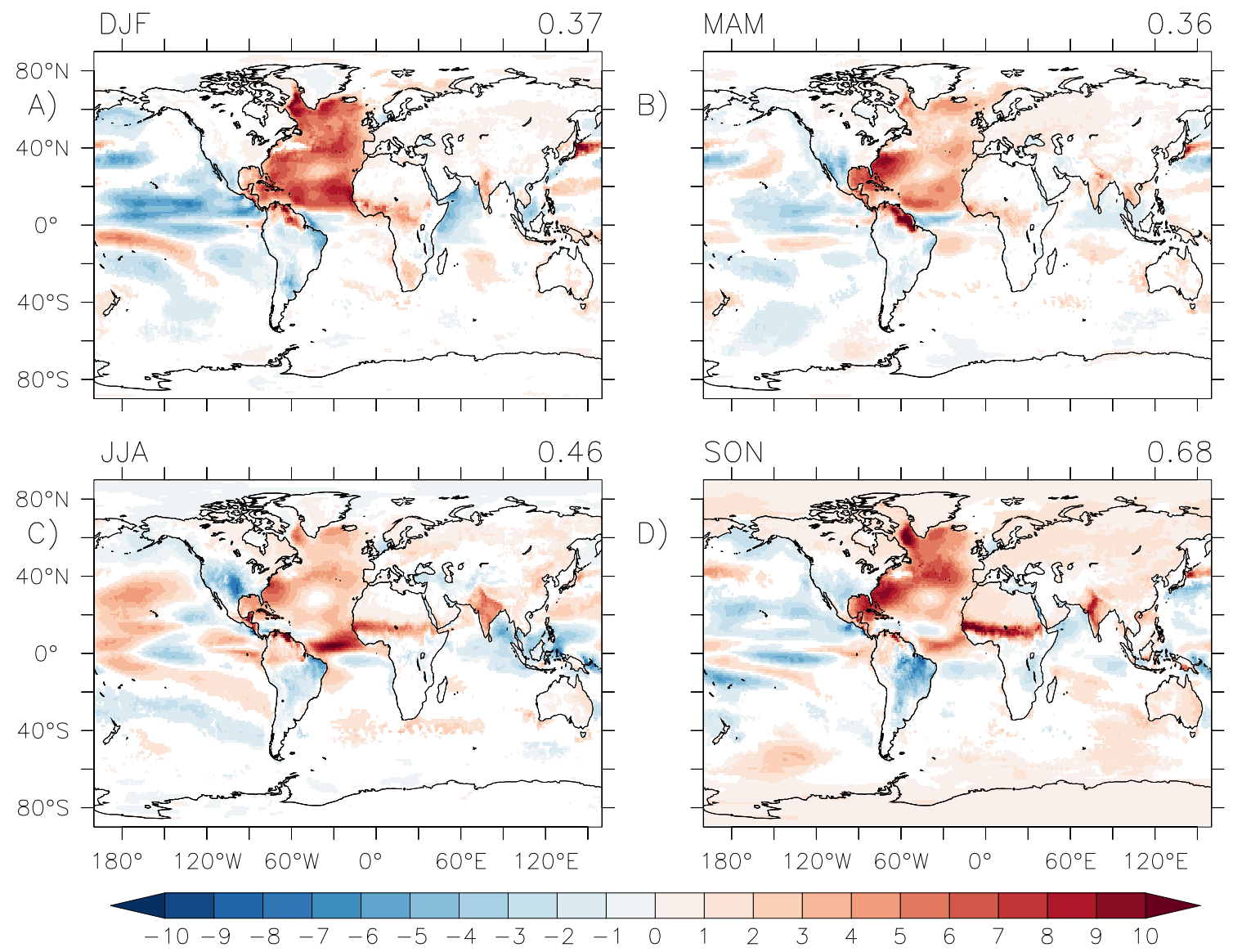

Fig. 5 As Fig. 2, but for surface upward latent heat flux. Units: $W / m^{2}$ (Note: values over land have not been multiplied by 10—unlike Fig. 6)

of the Pacific ocean; the most notable feature of which is the large high pressure anomaly in the Aleutian low region of the north Pacific. This feature persists throughout the year, peaking in winter (DJF, Fig. 3a) with a minimum in summer (JJA, Fig. 3c). Similar, but weaker, pressure anomalies over the north Pacific have been seen in previous atmosphereonly studies (e.g. Hodson et al. 2009; Sutton and Hodson 2007), suggesting the ocean may play a role in intensifying this response. Ruprich-Robert et al. (2017) and Lyu et al. (2017) demonstrate that that ocean atmosphere coupled feedbacks over the Tropical Pacific do enhance this AMV Pacific response

There are widespread circulation impacts over land. The circulation changes over Europe arising from the low pressure response (Fig. 3) as discussed above, may partly explain the weak response in surface air temperature in the region during summer and autumn (Fig. 2c, d); the increased northerly flow bringing colder polar air in the region, partly counteracting any local warming. The large Atlantic low pressure anomaly at $40^{\circ} \mathrm{N}$ during winter (DJF, Fig. 3a) leads to an equator-wards displacement of adjustment of the winter jet (SI section 2-Figure S12). Ruggieri et al. (2021) see a similar displacement of the jet in AMV-forced experiments; although they find the extratropical Atlantic circulation response is a weak North Atlantic Oscillation (NAO-) pattern, whereas Fig. 3a projects more onto the East Atlantic Ridge Pattern (Cassou et al. 2004).

Over North America the circulation response peaks in summer (JJA, Fig. 3c). This response, a low pressure anomaly extending over much of the southern US, with a maximum over the Gulf of Mexico, is characteristic of the Gill off-equatorial pressure response to off-equatorial heating (Gill 1980); where a latent heat anomaly (due to increased precipitation) north of the equator drives a stationary Rossby Wave, a surface low pressure anomaly, northwest of the heating source. Such a summertime circulation response has been seen in previous atmosphere-only studies (Sutton and Hodson 2005; Hodson et al. 2009). Whilst, the intensification of the western Pacific subtropical high (Zhou et al. 2009) near $20^{\circ} \mathrm{N}$ in the Northwest Pacific during summer (JJA, Fig. 3c) is likely to drive significant changes in East Asian climate (Monerie et al. 2020). 

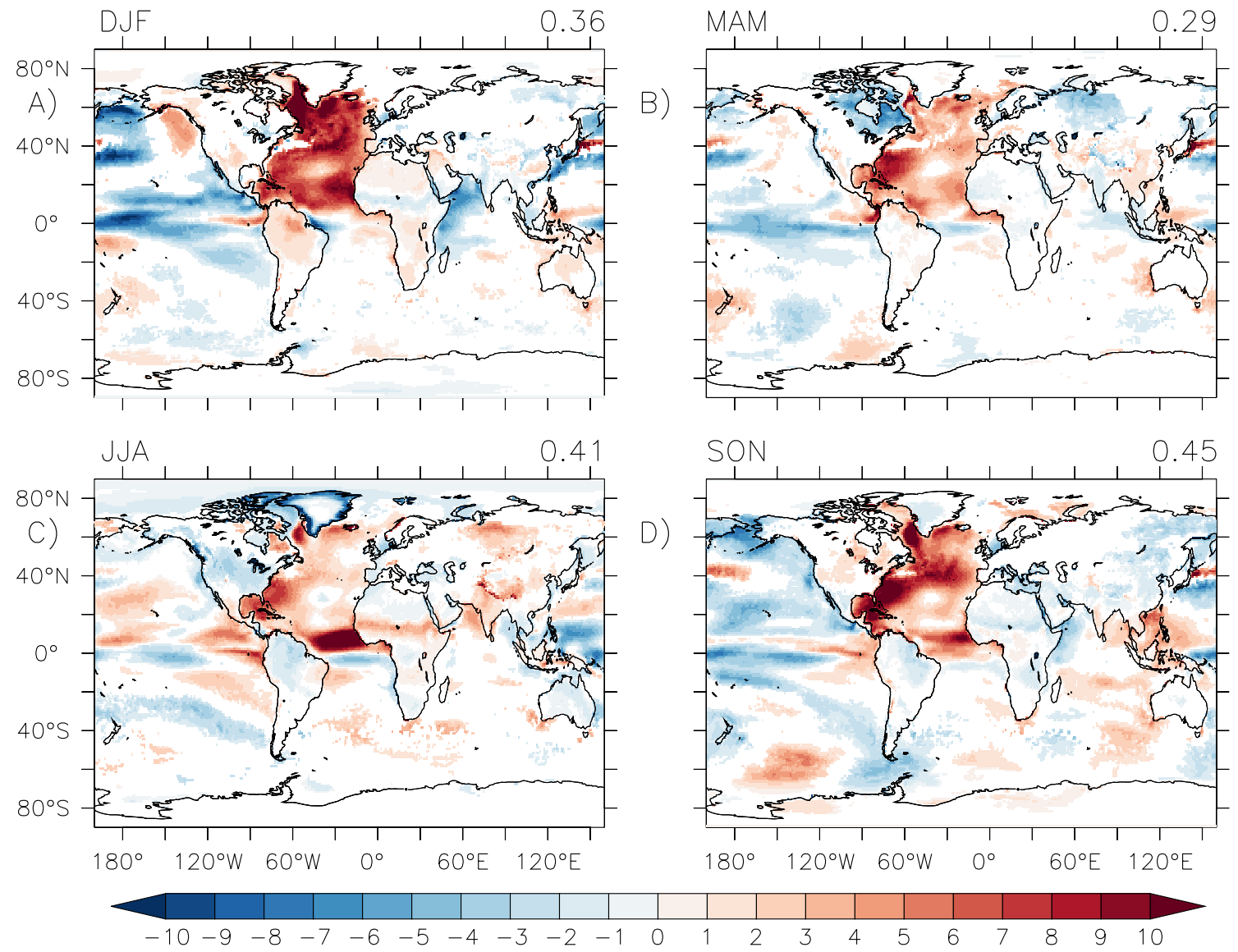

Fig. 6 As Fig. 2, but for net upward heat flux from the surface. Values over land have been multiplied by $\mathbf{1 0}$ to aid comparison. Units: $W / m^{2}$

\subsection{Surface heat fluxes}

The heat flux nudging used to maintain the $2 A M V^{+/-}$forcing pattern (Sect. 2.3) adds heat to the top ocean model layer at each timestep. Some of this additional heat will be mixed down into the ocean layers below, but the majority will be released into the atmosphere above the Atlantic Ocean. Across the models, the AMV drives a strong surface upward latent heat flux from the Atlantic (Fig. 5), with a strong seasonal cycle and a maximum in the winter months (DJF). The net surface upward heat fluxes from all fluxes (Fig. 6-note, land values have been multiplied by 10), which also peaks in the winter months, are generally greater in magnitude than the surface latent heat fluxes, although the latent heat fluxes makes the largest contribution in most regions (SI section 4-Figure S13).

The amplitude of net upward heat fluxes over land are smaller than over the ocean, but generally consistent with the pattern of surface air temperature changes (Fig. 2); suggesting that changes in surface heat fluxes drive the surface air temperature response. However, in western Eurasia, Alaska, and eastern Canada (Fig. 2a, b), where the surface flux contribution is weak, horizontal heat flux convergences within the atmosphere must play a greater role.

Changing surface shortwave fluxes drive surface air temperature responses in some regions. The summer and autumn cooling over sub-Saharan Africa and the Indian subcontinent, together with the northern South American cooling during winter and spring (Fig. 2) are all associated with a reduction in downwelling surface shortwave (Fig. 7). Similarly, the year-round warming response of North America and the spring (SON) warming over South America (Fig. 2) are both accompanied by increased surface shortwave. Both these responses are co-located with corresponding responses in precipitation (Fig. 4) and hence the positive (negative), surface air temperature anomalies are likely driven by reduced (increased) precipitation and cloud cover, leading to an increase (decrease) in downwelling shortwave, together with reduced (increased) upward surface latent heat fluxes due to reduced (increased) soil moisture which follow the circulation response to the AMV (see Ruprich-Robert et al. 2018). 

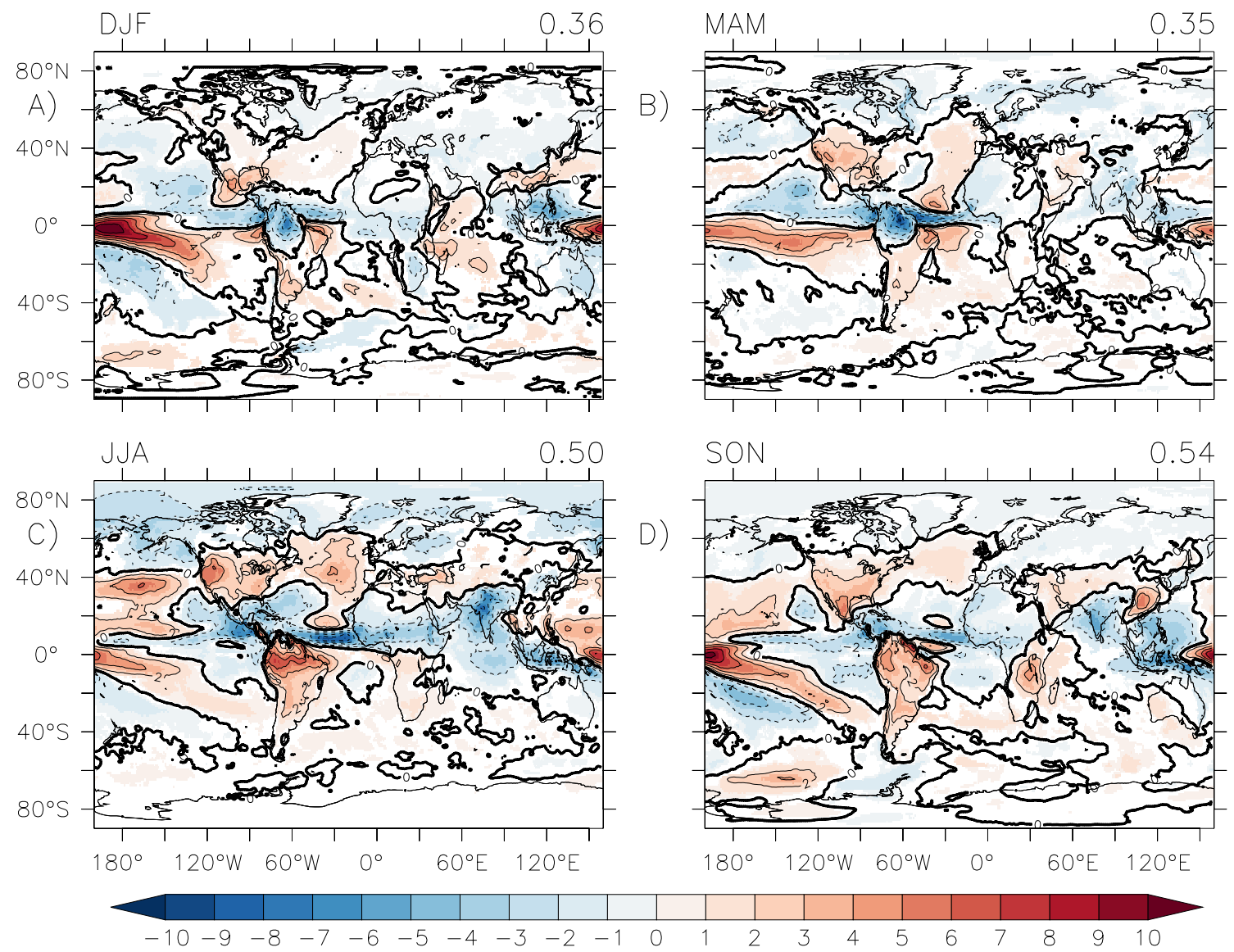

Fig. 7 As Fig. 2, but for downwelling surface shortwave (rsds). Units: $W / \mathrm{m}^{2}$. Contours: $2 \mathrm{~W} / \mathrm{m}^{2}$

\subsection{Pacific ocean response}

Over much of the Pacific Ocean (especially the tropical region), there is a net downward flux into the Pacific Ocean (Fig. 6), demonstrating that the heat flux forcing from the Atlantic is largely being absorbed by the Pacific Ocean (stronger in winter (DJF), weaker in summer (JJA)), with the western Indian Ocean also contributing in winter (DJF). Comparing the surface air temperature (Fig. 2-or SST SI section 2-Figure S10) and net heat flux in the region, it is clear that the eastern and central Pacific cooling is not a direct response to net surface heat fluxes-which are generally acting to warm the ocean surface. The cooling must partly arise from the ocean response-for example, increased upwelling of colder subsurface waters, driven by changes in the surface winds (via Ekman pumping).

This widespread east Pacific cooling (Fig. 2) is a robust feature of many coupled model studies examining the impact of a warmer Atlantic (McGregor et al. 2018; Kucharski et al. 2011; Li et al. 2016; Ruprich-Robert et al. 2021; Meehl et al. 2021). Overall, the Pacific response to the AMV can be understood as follows. Warmer North Atlantic SSTs (Fig. 2) increase the latitudinal SST gradient, driving the
ITCZ further north (Fig. 4). This displacement results in anomalies in convection and latent heating release aloft over the Tropical Atlantic. Such anomalies will drive changes in the Tropical Walker Circulation (Rodríguez-Fonseca et al. 2009; Kucharski et al. 2011), leading to enhanced descent, increased surface pressure (Fig. 3) and surface easterly wind anomalies over the eastern Pacific Ocean (Li et al. 2016; Meehl et al. 2021). These surface easterly wind anomalies drive surface cooling and increased Ekman upwelling of colder subsurface waters, leading to cooler SSTs (England et al. 2014; Li et al. 2016; Ruprich-Robert et al. 2021; Meehl et al. 2021). The resulting east-west temperature gradient may then be intensified further via the Bjerknes feedback (Bjerknes 1969; Wang 2018). Such a widespread Pacific cooling could be viewed as a global negative feedback to the imposed SST forcing; attempting to return the climate system to its mean state.

The Pacific cooling intensification will be accompanied by changes in subsidence and convection, which may drive mid-latitude changes. Further examination of the upper level circulation (Fig. 8) reveals a wavetrain originating from the Tropical Pacific with a path extending into the north Pacific and over North America; reminiscent of the Pacific-North 

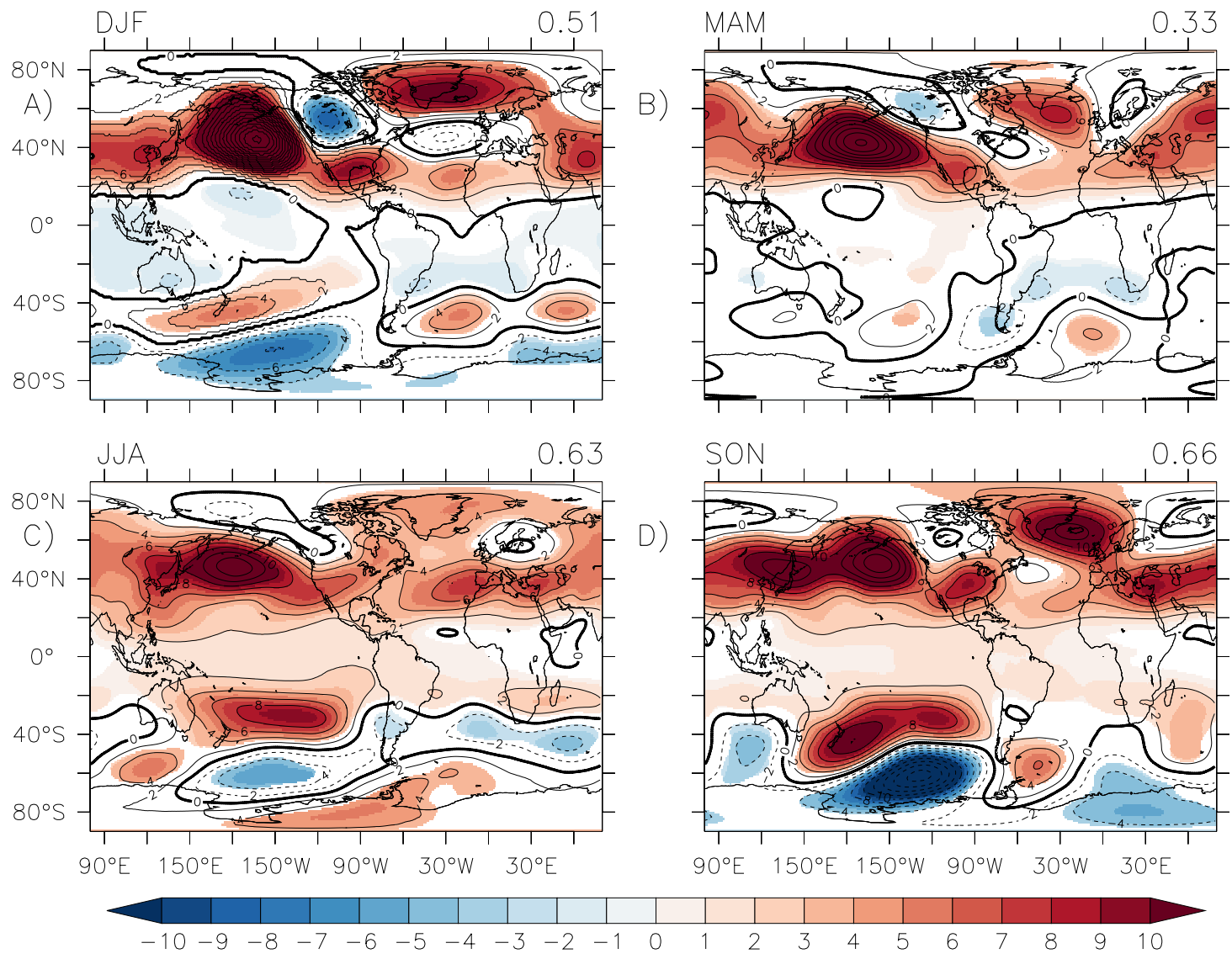

Fig. 8 As Fig. 2, but for 500 hpa geopotential height (zg). Units: $m$. Contours: $2 m$

American (PNA) pattern (Wallace and Gutzler 1981), and mirrored to a certain extent in the Southern Hemisphere. This upper level response is partly reflected in the surface pressure response in winter and spring (strongly over the north Pacific, weakly over Canada and Greenland-Fig. 3). Similar wavetrain responses were found in both CM2.1 and CESM1 by Ruprich-Robert et al. (2017), but there was a notable differences in the two models responses.

\subsection{Model dependence}

We now examine how the AMV response varies across the five models (averaging over resolution and ensemble members) - where do they significantly disagree in their response to the AMV? We must acknowledge that our five models are not a representative subsample of all current global climate models (e.g. Knutti et al. 2013), and so our assessment here is not a precise estimate of the model uncertainty in the AMV response, but more an assessment of which regions and aspects of the response show significant model uncertainty. We examine this dependence using the $A_{e m}$ term in the ANOVA model (Sect. 3). If $A_{e m}>0$, this implies that the spread of the individual model responses around the multi-model mean response (Figs. 2, 3, 4) is greater than the internal variability ( $\epsilon$-Eq. 3 ). Since there are more than two models, we examine the fraction of the total variance $\left(F V E_{A}\right.$-see Appendix A ) in $X_{e m r j}$ that is explained by $A_{e m}$, rather than the mean difference between $2 A M V^{+}$ and $2 A M V^{-}$as we examined above. When this fraction is large compared to the fraction of the total variance explained $\left(F V E_{\alpha}\right)$ by the experiments $\left(\alpha_{e}: 2 A M V^{+}, 2 A M V^{-}\right)$we can conclude that there is considerable model spread around the multi-model mean response. We therefore show the ratio of the two $\left(F V E_{A} / F V E_{\alpha}\right)$ in the following figures. We plot this ratio where $A_{e m}$ is a significant effect in the ANOVA $(p<0.05)$. Additionally, we stipple shade where $A_{e m}$ is a significant ( $p<0.05$ ), but $\alpha_{e}$ is not ( $\left.p \geq 0.05\right)$. This allows us to examine where the significant responses in Figs. (2, 3, 4) are highly consistent across models, or subject to greater model spread. The following results are also robust to subsampling (see SI section 1.2). 

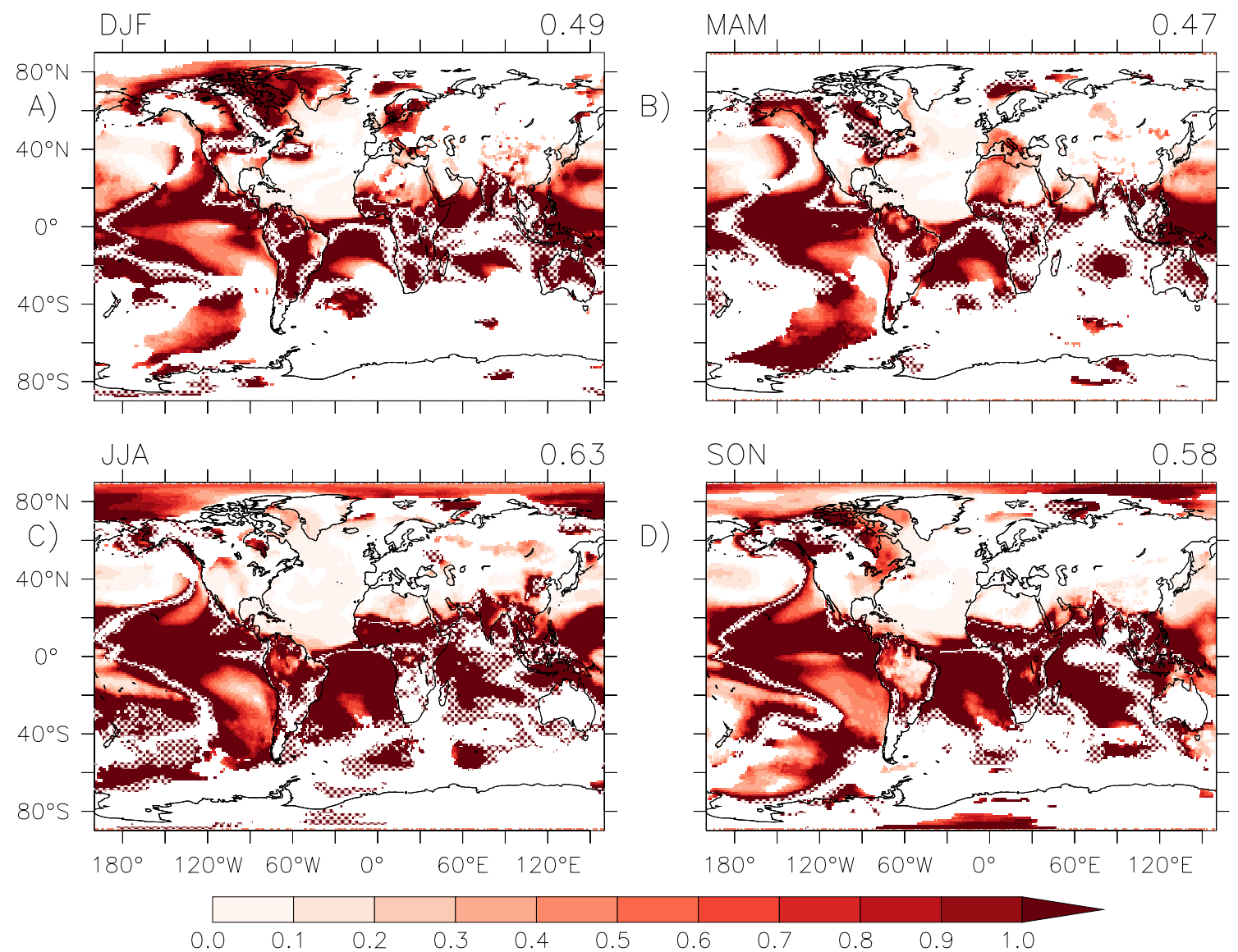

Fig. 9 Impact of model choice on the seasonal mean Surface Air Temperature (tas) AMV response. For each season we plot the fraction of the total variance in the ensemble explained by the model-experiment term $\left(A_{e m}\right.$, Sect. 3 eq. 3$)$ divided by the fraction of the total variance explained by the experiment term $\left(\alpha_{e}\right)$. Dark red regions hence show where the models disagree on the AMV

\subsubsection{Surface air temperature}

Figure 9 shows variation of the surface air temperature (tas) responses to the AMV across the five models as discussed above, larger values highlight where the model spread in the AMV response is large compared to the model mean response.

Over the North Atlantic, model spread is low-implying that the SST nudging methodology (Sect. 2.3) is generally successful in applying a consistent SST anomaly across the models (assuming that SST and surface air temperature are closely coupled, which they appear to be (SI section 2-Figures S10)).

The tropics see significant model divergence in the response, particularly over the oceans. The Central Pacific and South Atlantic coolings responses (Fig. 2) show notable variation across models.

Over northern hemisphere land, models generally agree on the temperature (tas) response, with some exceptions over response. Shading shows where $A_{e m}$ is significant $(p<0.05)$. Stippling show where $A_{e m}$ is significant, but $\alpha_{e}$ is not. A Winter (DecJan). B Spring (Mar-May). C Summer (Jun-Aug). D Autumn (Sep-Nov). Top right of each panel: fraction of the total number of gridpoints that are significant $(p<0.05)$

North America in winter (Fig. 9a) and Europe and northern Africa in winter and spring (Fig. 9a, b).

There is larger model spread over tropical and southern Africa, and northern South America. These may be the result of variations in the extent of the northward displacement of the ITCZ across the models in response to the AMV. This northward displacement (Fig. 4) is associated with a band of cooling (Fig. 2)-a latitudinal spread in these cooling regions across the models will result in considerable spread in the model temperatures in the affected regions. The Arctic shows considerable spread in summer and autumn, suggesting a divergent response of the seasonal sea ice melting across the models.

Part of the large spread in the Pacific and South Atlantic temperature response may be due to a larger cooling response in MPI-ESM 1.2-excluding this model from the ensemble results in a smaller model spread and reduced Pacific cooling (SI section 6-Figures S29 and S32). 

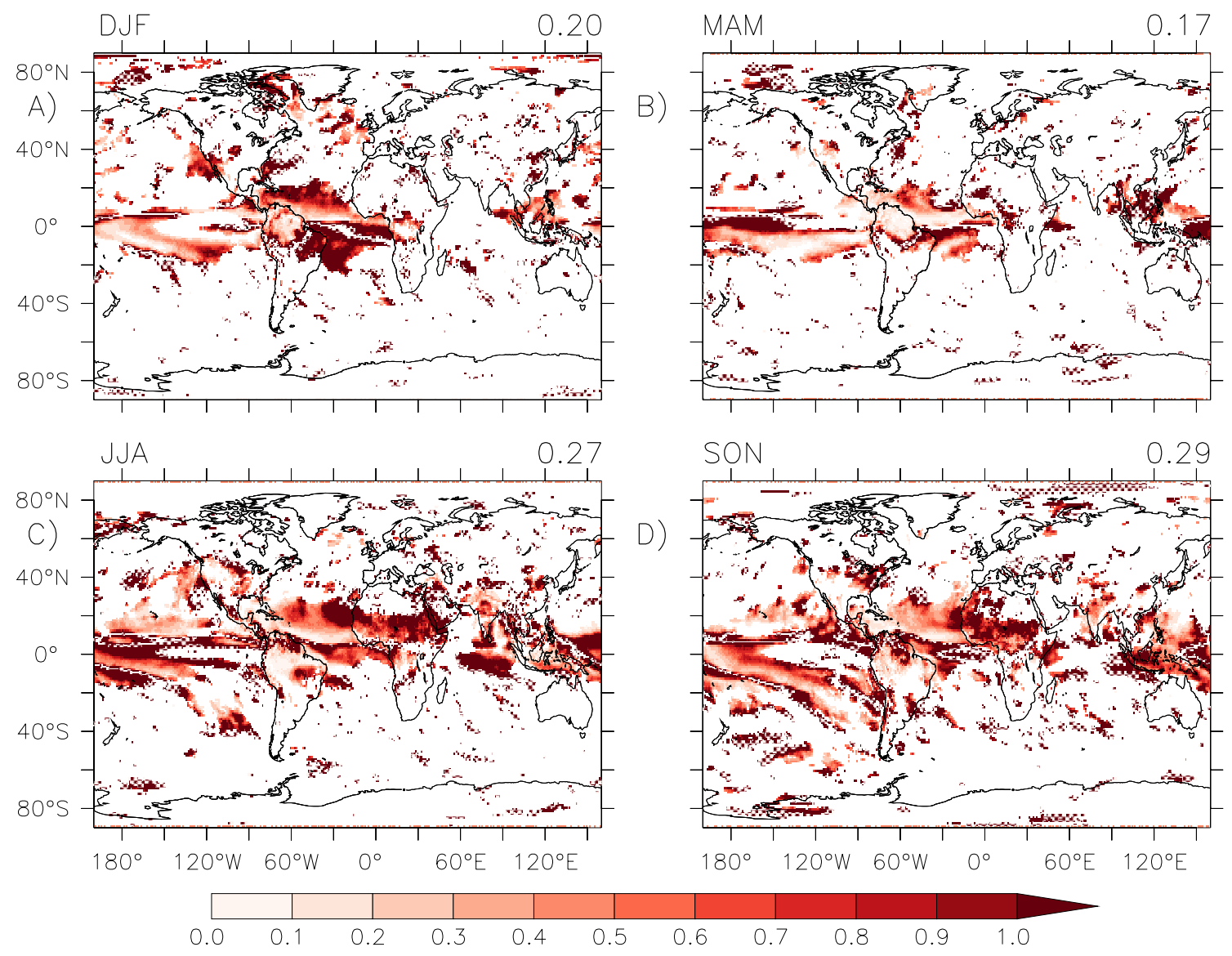

Fig. 10 As Fig. 9, but for precipitation (pr)

Overall, the spread in temperature responses suggests the models generally agree on the northern hemisphere extratropical response to the AMV ( $A_{e m}$ is not significant-hence the spread in the responses across models is smaller than the internal variability $\epsilon$ in 3-see Appendix Eq. 10), however there is significantly less agreement over the tropical response $\left(A_{\text {em }}\right.$ is significant-the spread in the responses across models is larger than the internal variability $\epsilon$.)

\subsubsection{Precipitation}

Outside the tropics, and particularly over land, the precipitation response to the AMV is generally consistent across the models (Fig. 10). Over the US, there is some notable model spread, particularly during summer (JJA).Within the tropics, model spread is greatest over the Tropical Atlantic throughout the year. This spread extends over Sub-Saharan northern Africa in summer (JJA) and autumn (SON) (Fig. 10c, d) and throughout the year over northern South America. This is likely due to variations in the northward displacement of the ITCZ across the models (Fig. 4), a common feature in AMV studies (e.g. Sutton and Hodson 2005; Mohino et al. 2011; Zhang and Delworth 2006). As ITCZ displacements are driven by changes in the cross-equator SST gradient, model spread in the ITCZ may be driven by the spread in the South Atlantic SST response (Fig. 2).

The model spread over the Tropical Pacific and the Maritime continent, key regions of subsidence and ascent, suggest a spread in the models tropical Walker circulation responses to the AMV. Excluding the MPI-ESM1.2 model from the ensemble reduces this spread, but the overall pattern of spread is similar (SI section 6-Figures S31 and S34).

\subsubsection{Mean sea level pressure}

The local response to the AMV forcing over the North Atlantic is generally consistent between models (Fig. 11), but consistency is weaker over the Tropical Atlantic, particularly in summer and autumn (Fig. 11c \& d); this may be related to the spread of the ITCZ response across the models (see above).

There is significant diversity across the models over the Maritime Continent, possibly as a result of varying ascent in the region due to a divergence in the response of the Walker Circulation to the AMV across models. 

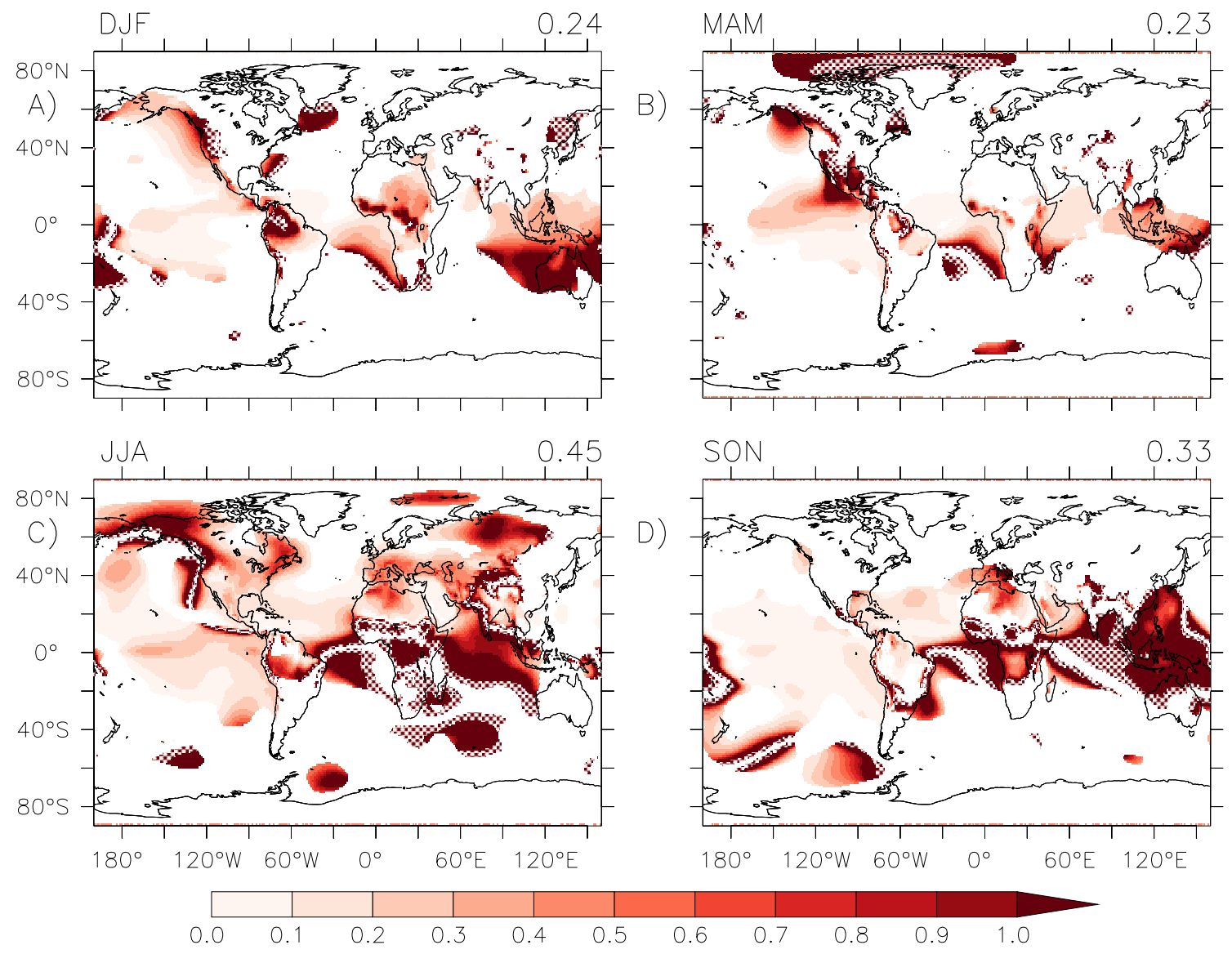

Fig. 11 As Fig. 9, but for mean sea level pressure (psl)

Summer (JJA, Fig. 11) is the season showing the greatest model diversity in the response, this season also shows the greatest model diversity in the circulation over the Indian Ocean, which may imply a diversity in the South Asian monsoon response.

\subsubsection{Extratropical Wavetrain}

The extratropical wavetrain response in our ensemble (Fig. 8) is generally consistent across models, as shown by the ANOVA for geopotential height in Fig. 12, but there are some inter-model variations in the strength and position of the negative Canadian and positive Icelandic $500 \mathrm{hpa}$ height lobes in winter. These variations may arise from the differences in the strength of the Pacific response to the AMV across the models (Fig. 9), or also differences between models in their mean state upper level flow, which may modify the path of atmospheric Rossby wave propagation from the Tropical Pacific (Scaife et al. 2017). The impact of the AMV on the Pacific in these and other AMV experiments is discussed in depth in Ruprich-Robert et al. (2021).

\subsection{Impact of resolution}

Finally, we examine the impact that model resolution has on the modelled response to the AMV.

As horizontal model resolution is increased, both in the atmosphere and ocean, more small-scale processes are better resolved, sharp gradients associated with frontal systems and topography are better represented; models generally begin to better represent the observed climate. Increasing atmosphere resolution improves model climate; leading to reduced tropical biases (Jung et al. 2012), better representation of northern hemisphere blocking (Berckmans et al. 2013; Schiemann et al. 2017), leading to changes in eddy feedbacks and the representation of frontal structures (which can influence the position of the jet (Czaja et al. 2019)) and leading to enhanced moisture transport from ocean to land (Demory et al. 2014). Increasing the ocean resolution also improves multiple aspects of the ocean mean state compared to observations (Hewitt et al. 2017). The improved representation of ocean eddies and resolution of topography (Hurlburt et al. 2008) can lead to improved position and representation of the western boundary currents (Marzocchi et al. 2015) leading 

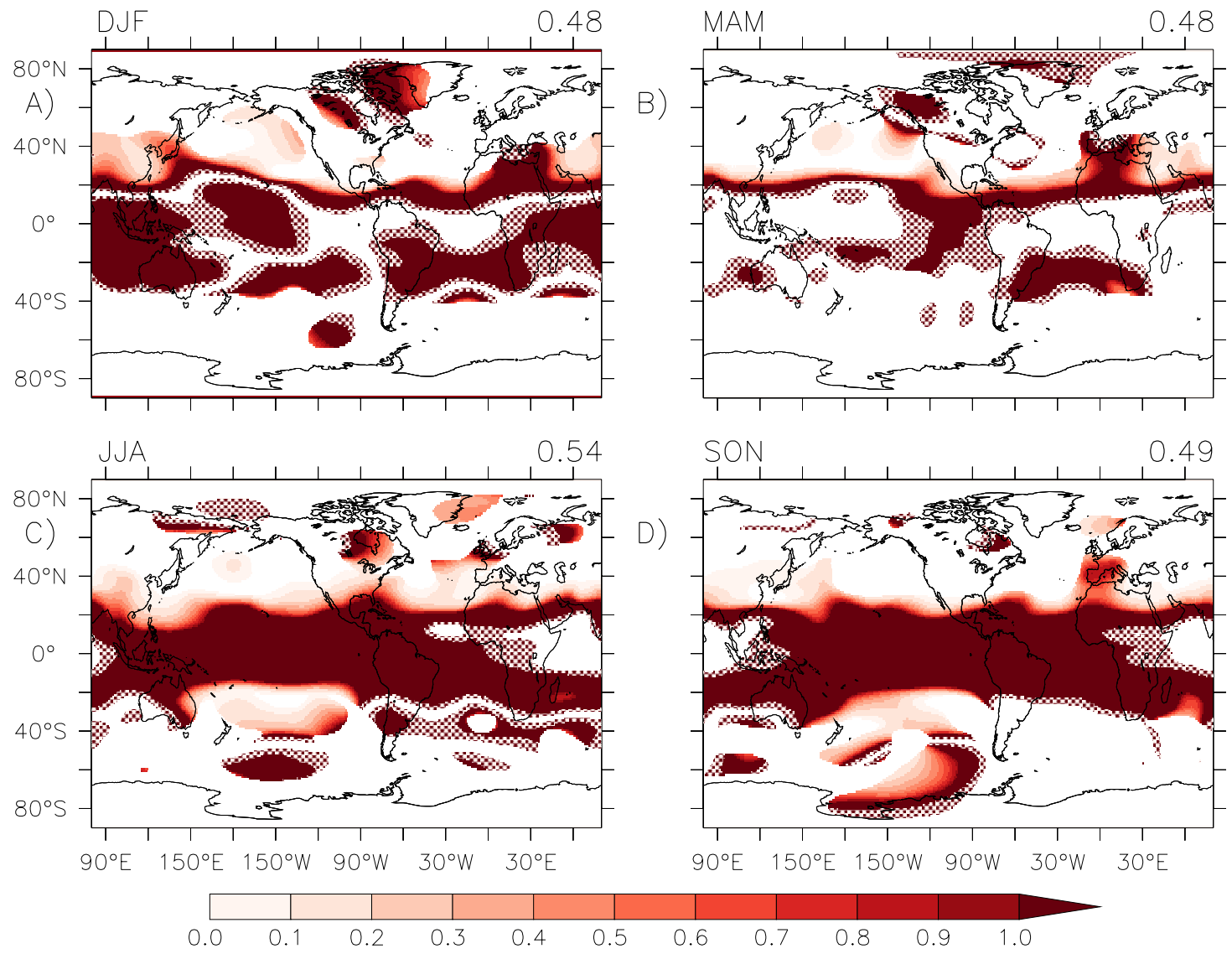

Fig. 12 As Fig. 9, but for 500 hpa geopotential height (zg)

to reduced SST biases. The resulting sharper SST gradients can significantly influence the overlying atmosphere (Minobe et al. 2008; Parfitt et al. 2016). The increase of model resolution can also lead to changes in the variability of ocean models (Hodson and Sutton 2012; Jackson et al. 2020).

All these aspect demonstrate that increasing horizontal resolution in climate model studies can lead to changes in the mean climate state. For some processes, model climate may change or improve continuously with increasing resolution (Demory et al. 2014), for other processes changes may occur as a critical resolution threshold is passed after which key processes are explicitly resolved, for example atmospheric convection (Fosser et al. 2015), ocean eddies (He et al. 2018), or Rossby radius (Hewitt et al. 2016). These impacts of increasing climate on model resolution suggest that the response of the climate to the AMV may also vary with resolution. We attempt to address this question in the following section.

Experiments were performed at both high and low atmosphere resolution, but examination of Table 1 shows that comparing model resolution between models is dependent on how resolution is defined, due to the variation in grid geometries. It is also clear that there is no resolution threshold that divides the models into low and high resolution. This spread of model resolutions presents a challenge to assessing the impact of model resolution on the AMV response.

The change in the modelled AMV response due to resolution can be best expressed as a quadrature:

$D_{m}=\left(X_{+}^{H}-X_{-}^{H}\right)-\left(X_{+}^{L}-X_{-}^{L}\right)$

that is, the difference between the AMV response in the higher resolution models, and the AMV response in the lower resolution models. We can then propose two hypotheses:

1. $D_{m}$ is proportional to, or monotonic with the change in resolution $R_{m}\left(=R^{H}-R^{L}\right)$

2. $D_{m}$ is zero unless the low and high resolution models span a critical resolution threshold, $R_{c}$

We can examine these hypotheses using the ANOVA test for $G_{e r}$ (Eq. 3). If $G_{e r}$ is not a significant factor $(p<0.05)$, then we are unable to reject the null hypotheses that the 

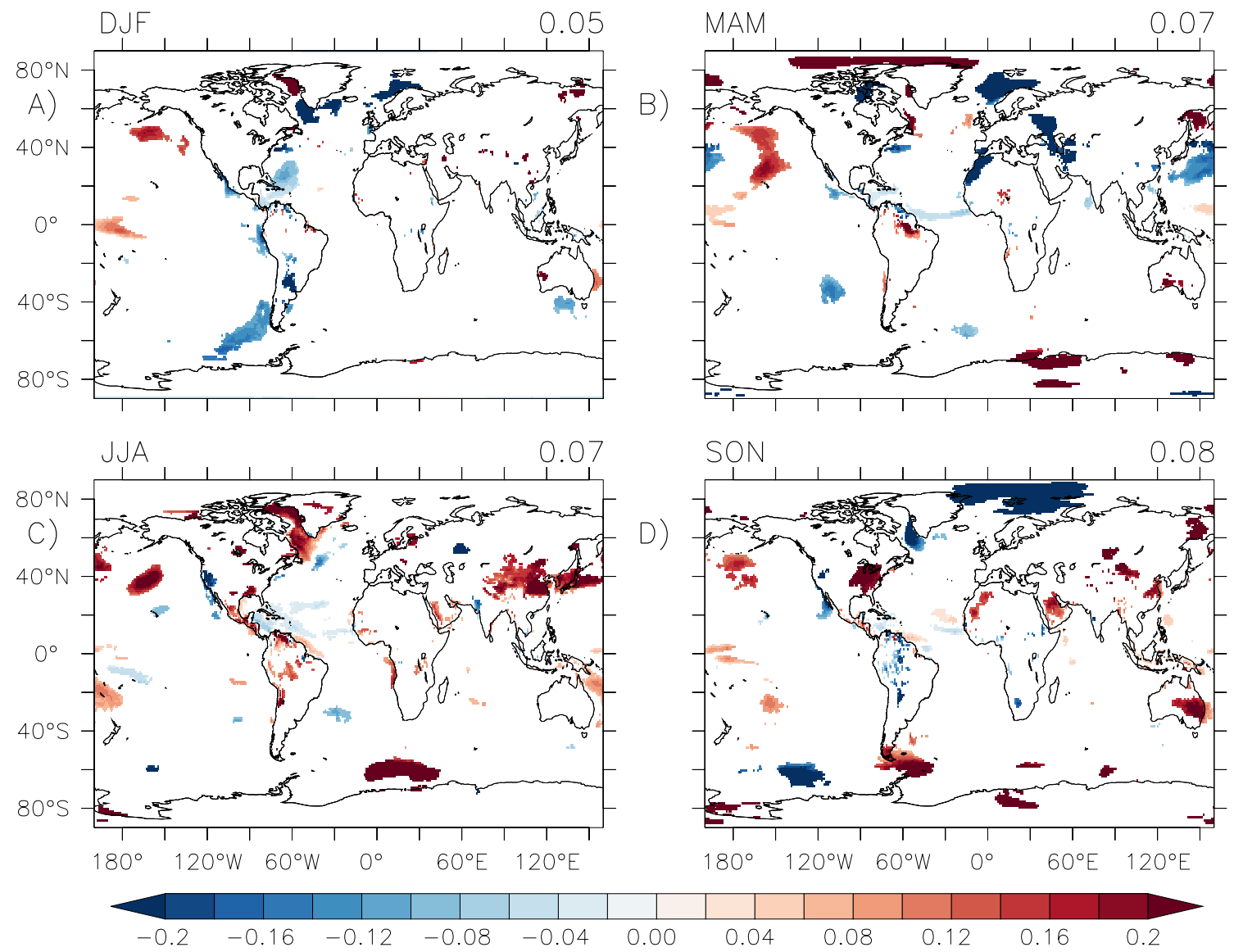

Fig. 13 Seasonal Surface Air Temperature (tas) - Impact of increasing model resolution on modelled AMV response. Each panel shows the difference between the AMV High Resolution (HR) ensemble responses $\left(2 A M V^{+}-2 A M V^{-}\right)$and the Low Resolution (LR) responses.
Regions where the difference is significant $\left(G_{e r} ; p<0.05\right)$ are shaded. A) Winter (Dec-Jan). B) Spring (Mar-May). C) Summer (Jun-Aug). D) Autumn (Sep-Nov). Units: C. Top right of each panel: fraction of the total number of gridpoints that are significant $(p<0.05)$ model mean of $D_{m}$ is zero. This could arise because none of the $D_{m}$ are greater than zero (the AMV response does not change as resolution is increased), or a threshold $\left(R_{c}\right)$ is spanned by a subset of the models $\left(\mathrm{m}^{\prime}\right)$, but the resulting $D_{m^{\prime}}$ are too small to be detected when meaned over all models.

Unlike in the previous sections, the significance of these results for resolution do appear to be somewhat sensitive to resampling (see SI section 1.3). Consequently, we only comment on the features that are robust to resampling in the following discussion. Additionally, we note that the field significance of many of these results is marginal.

Figures 13, 14 and 15 show that the impact of increasing model resolution is generally small; that is, we are unable to detect the impact of increased model resolution on the AMV response, although there are some regions where there are notable differences.

There are small significant changes in surface air temperature (tas) in the northern North Atlantic and Arctic in all seasons (Fig. 13), most notably in the Labrador Sea which sees colder (warmer) temperatures during DJF (JJA) at higher resolution, with a small cooling in the Barents Sea during MAM. These changes may arise due to resolution sensitivities in the mixed layer depth or sea ice, but could also arise from differences in the mean state of the sea ice cover in HR and LR controls - small differences in the mean sea ice extent could lead to large differences in the surface air temperature response between the resolutions. These changes are only marginally field significant, however.

The impact of resolution on the large scale circulation response is very weak and small compared to the mean response, with perhaps a slight positive mean sea level pressure response over southern South America in HR (Fig. 14 and SI section 1.3-Figure S8). But in none of the seasons are these results field significant.

The strongest impacts of increasing model resolution appears in the tropical precipitation response (Fig. 15). The AMV drives a northward displacement in the Atlantic ITCZ, represented by the dipole in Fig. 4. This northwards displacement is stronger in HR, resulting in a precipitation 

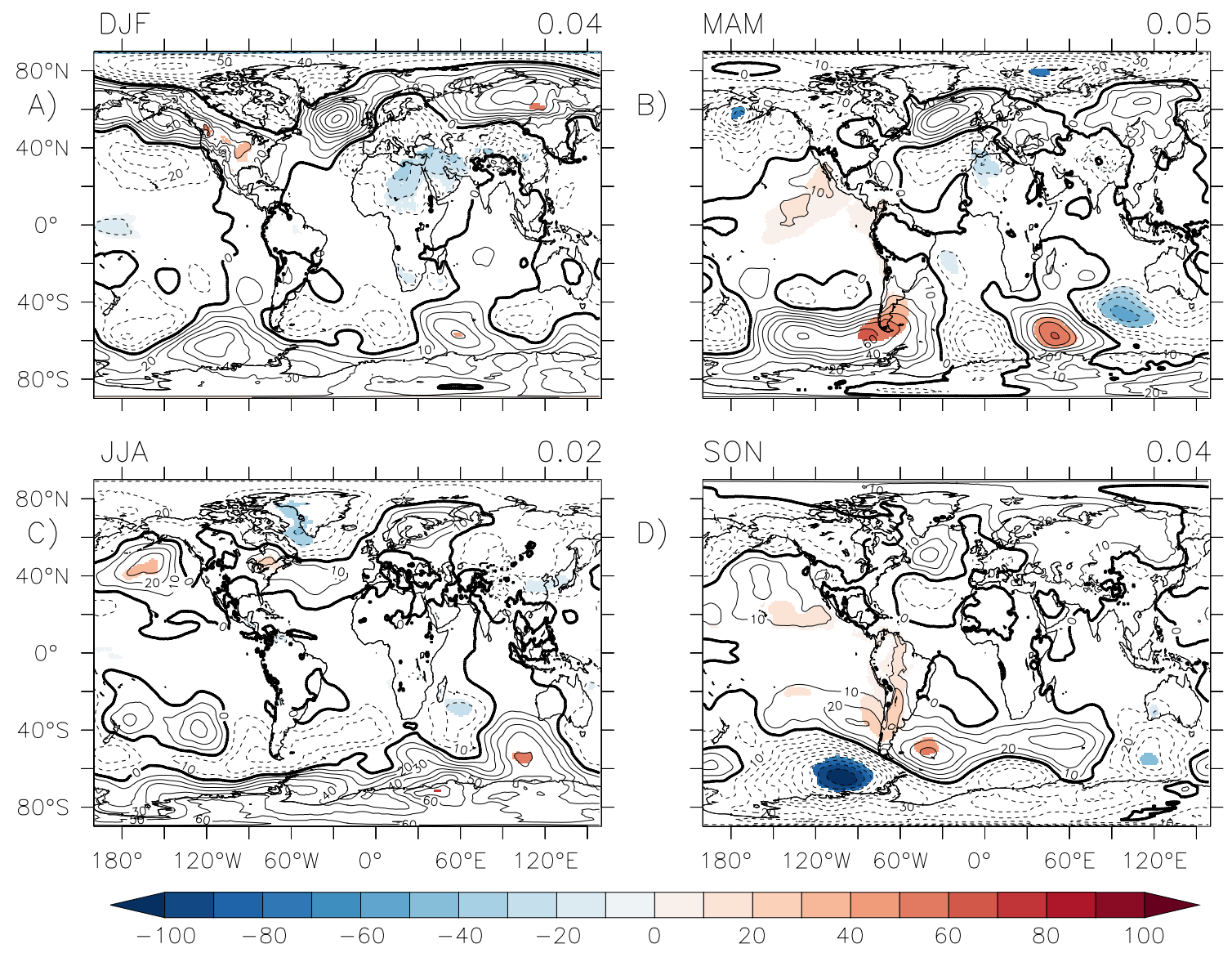

Fig. 14 As Fig. 13, but for mean sea level pressure (psl). Units: Pa Contours are $20 \mathrm{~Pa}$

tripole (difference between two displaced dipoles) in the Tropical Atlantic. This tripole is strongest in summer (JJA, Fig. 15c). This could arise due to an enhanced northern hemisphere warming response in the HR models during summer (Fig. 13c) (e.g. Frierson et al. 2013), which could drive a more northward shift in the ITCZ and the Hadley circulation.

There is also a small increase in precipitation over the west Pacific Ocean in winter and autumn (Fig. 15a, d), consistent with an enhanced ascent and a strengthening of the tropical Walker Circulation.

Because of the difficulty of distinguishing high and low resolution models across the ensemble, as discussed above, we can also examine the impact of resolution in individual models (see SI section 5-Figures S14-S28). This analysis shows that the models generally agree on the weak impacts seen across the full ensemble, but that the MPI-ESM 1.2 model shows a much stronger impact of resolution, with warmer temperatures over the wider Atlantic subpolar gyre, and a stronger Atlantic ITCZ displacement (SI section 5Figures S18 and S28).

Despite this diversity, we have not been able to detect a large scale change in the climate response to the AMV after an increase of horizontal resolution (Figs. 2, 3, 4). Small consistent impacts of increased resolution are small regional variations in surface air temperature (tas) over the Arctic together with a northward shift in the ITCZ.

\section{Discussion}

The global scale climate response to the AMV in the multimodel multi-resolution ensemble mean (Figs. 2, 3, 4) is in broad agreement with the findings of previous coupled AMV experiments (Ruprich-Robert et al. 2017; Dong et al. 2006; Levine -et al. 2018). Key features of the surface air temperature, pressure and rainfall responses identified above are also seen in these studies. This similarity suggests that the pattern of the climate response to the AMV is broadly consistent across coupled climate models, but the details and the magnitudes of the model responses may differ (McGregor et al. 2018; Kajtar et al. 2018; Ruprich-Robert et al. 2021). This climate response is also broadly similar to that found in previous atmosphere-only AMV studies (Hodson et al. 2009; Sutton and Hodson 2007; Mohino et al. 2011; Davini et al. 2015; Peings and Magnusdottir 2014; Zhang and Delworth 

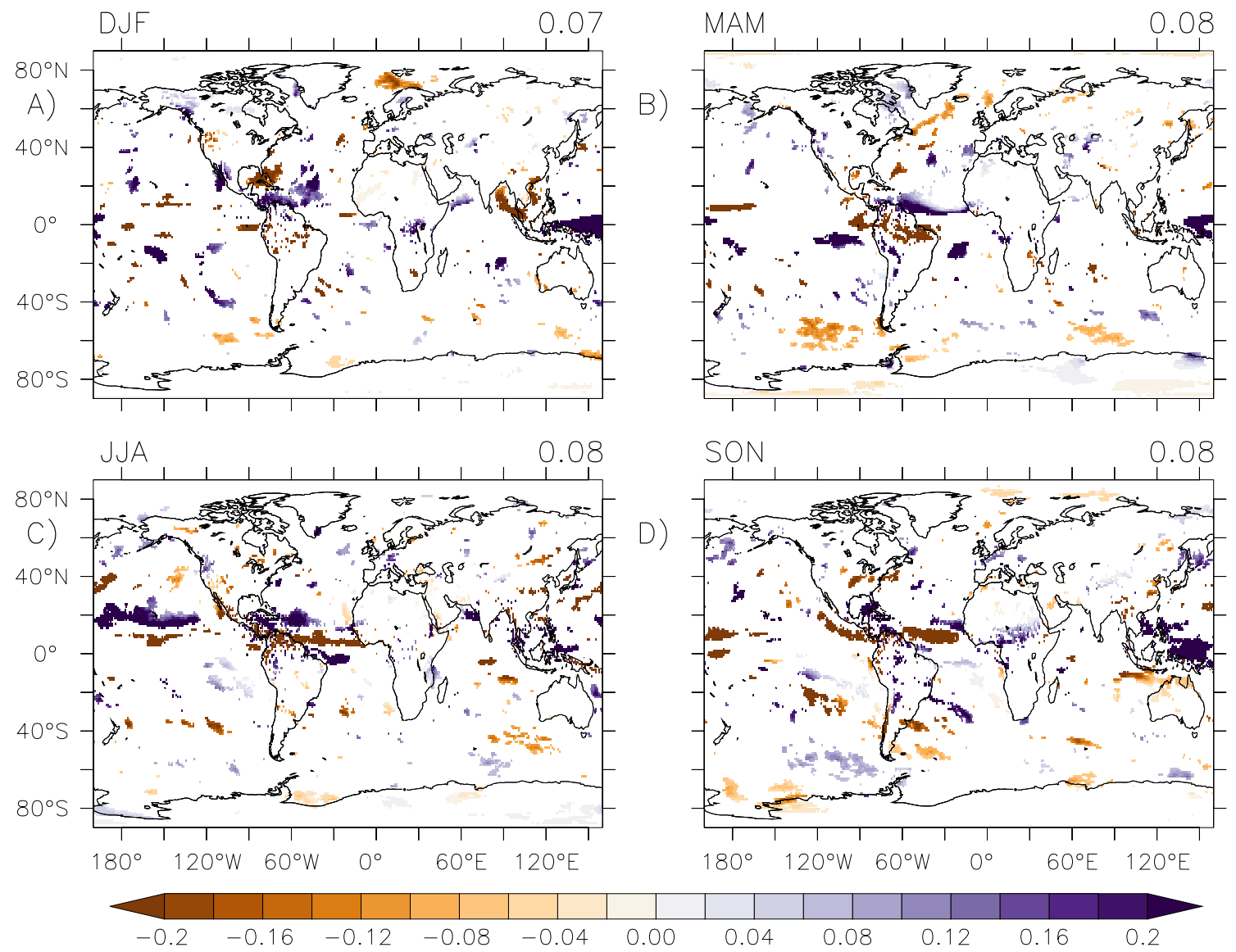

Fig. 15 As Fig. 13, but for precipitation (pr). Units:mm/day

2006), however the response over the fixed-SST oceans in those experiments is generally weaker than seen in the coupled studies, suggesting that ocean-atmosphere coupling enhances the climate response to the AMV.

We have examined the difference between the $2 A M V^{+}$ and $2 A M V^{-}$experiments, but does the climate respond differently to $2 A M V^{+}$and $2 A M V^{-}$? In other words, how linear is the climate response to the AMV around the model climatology? We can examine this question by comparing both AMV responses to the model climatology (SI section 8Figures S37-43). We conclude that the large-scale climate response is mostly linear-that is the $2 * A M V^{+}-$Clim and Clim $-2 * A M V^{-}$responses have the same spatial structure as the $2 * A M V^{+}-2 * A M V^{-}$response (Figs. 2-4). We discuss this further in the SI (section 8 ).

Each model realization was integrated for 10 years. In our previous analysis we assumed that each of these years is statistically independent. If the climate response to the AMV forcing evolved over time (i.e. drifted), then this would be an incorrect assumption. To test this independence we can examine the influence of the year of the realization in a similar way to the influence of the models (Sect. 4.4-Figs. 9, 10), and ask the question: does this factor significantly affect the AMV response? Figures S44-S46 (SI section 9) demonstrate that there are only small regional impacts of this factor. In other words, the climate response to the AMV is largely constant across the 10 years of simulation (see SI section 9 for more details).

\subsection{Comparison with observations}

How does the modelled response to the AMV compare with estimates of the observed response? The observed climate evolved in response to multiple sources of forcings, not just the AMV, hence it is challenging to derived a robust estimate of the true observed response to the AMV. Previous observational studies have attempted this, and some show a similar European warming (Fig. 2) in observations (Gastineau and Frankignoul 2014; O'Reilly et al. 2017; Sutton and Dong 2012). The modelled circulation response (Fig. 3) is less consistent and does not show the negative NAO response seen in Gastineau and Frankignoul (2014) or Peings and Magnusdottir (2014). The pattern of the precipitation response (Fig. 4) is broadly consistent with the increase over Europe seen by O'Reilly et al. (2017) and Sutton and Dong (2012), and with the observed increases over the Sahel 

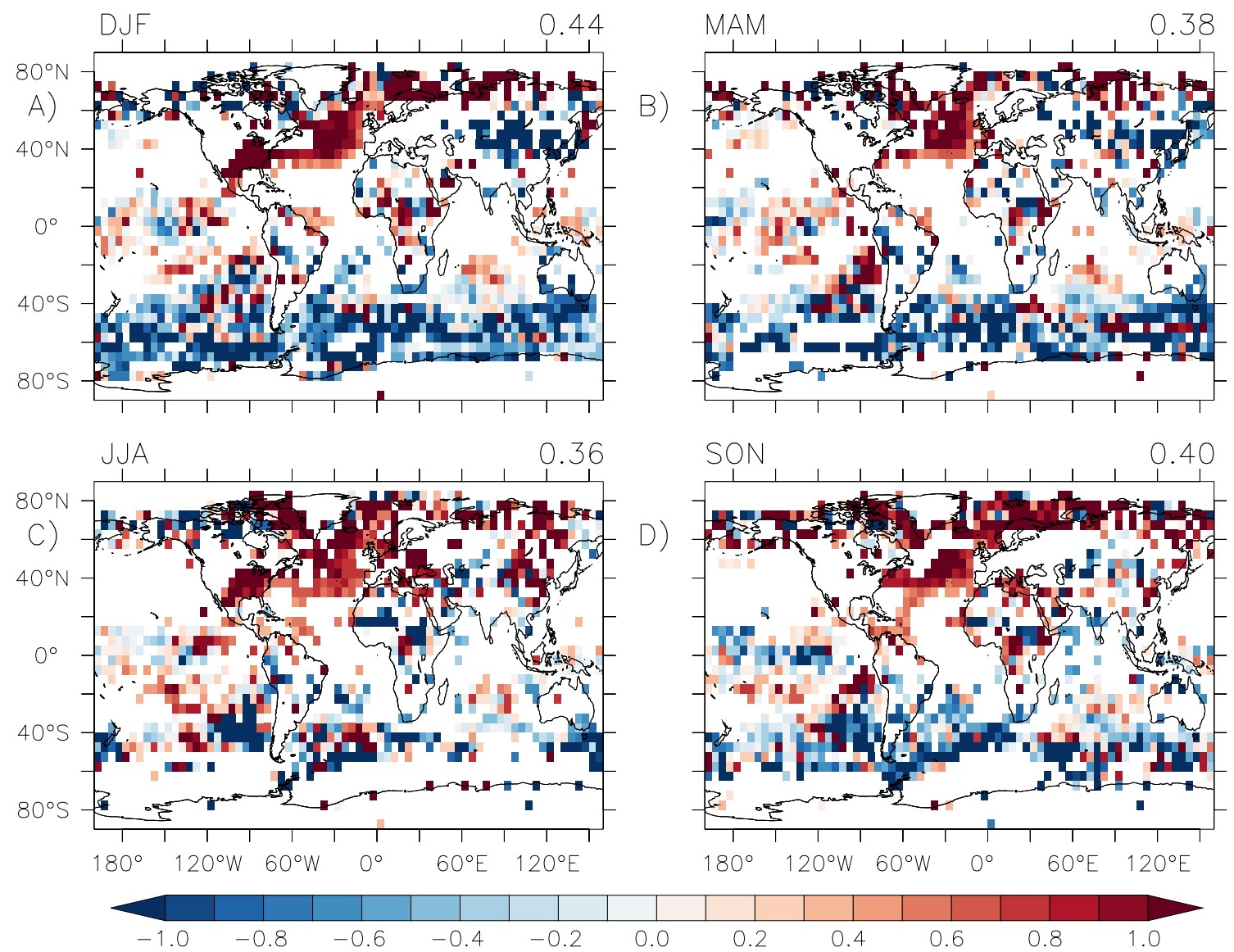

Fig. 16 Scaled (x2) composite of observed surface air temperature (tas, HadCruT) - 1930:1959 minus 1960:1989. The estimated forced trend has been removed from tas before computing the composite.
Shaded regions are significant (two-sided t-test between the two time periods, $p<0.05)$. Units $K$. Top right of each panel: fraction of the total number of gridpoints that are significant $(p<0.05)$
(Folland et al. 1986; Zhang and Delworth 2006), northeast Brazil (Uvo et al. 1998; Folland et al. 2001) and the reductions over North America (Sutton and Hodson 2005; Hodson et al. 2009).

Another approach to estimate the observed forced AMV response is to follow the method used to estimate the AMV forcing patterns (https://www.wcrp-climate.org/wgsip/ documents/Tech-Note-1.pdf), by removing an estimate of the forced historical warming trend (from a historical forced multimodel ensemble mean-Figure 1a from Technical Note) from observed SSTs. Averaging the resulting residuals over the North Atlantic gives the (detrended) AMV index (Fig. 1b).

We can follow the same approach with any observed field: removing the estimate of the forced trend (from Technical Note Figure 1a, above) and considering the residuals as an AMV response. We can then form a composite difference from residuals between a high-AMV period (1930:1959) and a low-AMV period (1960:1959) (Fig. 1b). Figures 16 and 17 show these differences for surface air temperature (HadCRUT4—see Sect. 2.4.1) and mean sea level pressure
(HadSLP2-see Sect. 2.4.1); the observed record of precipitation is too short for this approach. (We have multiplied these composites by 2 to aid comparison with the $2^{*} \mathrm{AMV}$ model responses previously shown.) An alternative approach is to composite based on when the AMV index (Fig. 1b) exceeds (falls below) plus (minus) one standard deviation. This approach produces similar results (SI section 7: Figures S35 and S36). Figures 16 and 2 show some consistencies between the modelled and estimated observed surface temperature response to the AMV: the warm anomaly of North America in DJF, extending to western Europe in JJA, and the cool Sahel anomaly band in JJA. Over the oceans, the cool Southern Ocean is consistent with the modelled response in most seasons, and the signal of eastern tropical Pacific cooling seen in the models is detectable in most seasons. The consistency is much lower for mean sea level pressure (psl) (Figs. 17 and 3). The greatest consistency appears in JJA, with a low pressure anomaly over North America, extending eastwards over the Atlantic to Europe. There is a hint of the modelled Aleutian high pressure response in DJF and JJA. Alternatively, we can examine the amplitude of the 

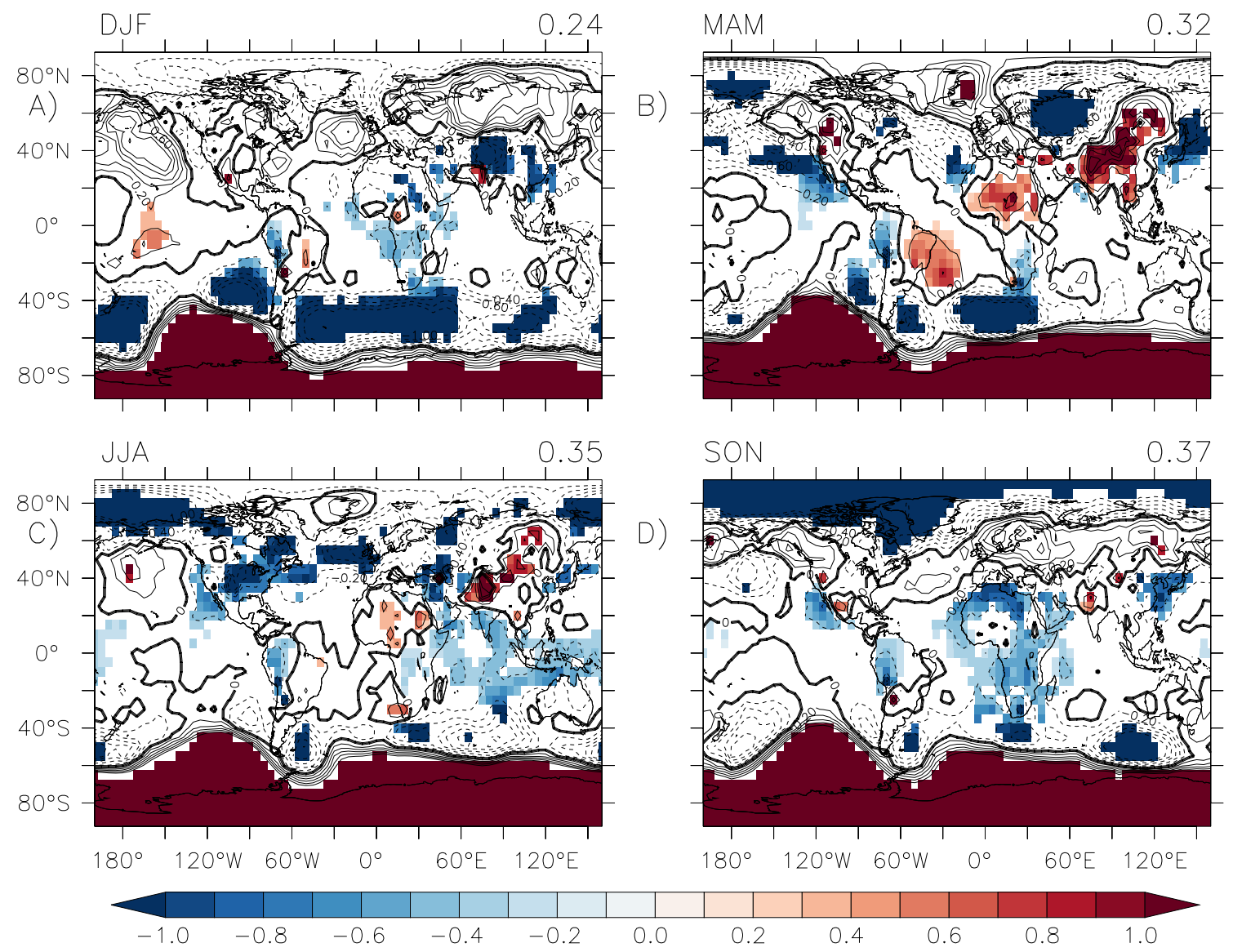

Fig. 17 As Fig. 16, but for mean sea level pressure. Units: $P a$

modelled AMV response compared to an observed estimate. This approach is motivated by the signal-to-noise paradox observed in seasonal forecasts; where the forecast amplitude of the North Atlantic Oscillation is about one-third of the observed amplitude (Scaife et al. 2014; Scaife and Smith 2018). If we project the observation residuals (i.e. detrended as above) onto the modelled response (Figs. 2 etc), we can estimate a timeseries $(\beta(t))$ of the observed response to the AMV for any variable (see SI section 7 for further details). If the real climate responds to the AMV with the same spatial pattern as the model, then $\beta(t)$ would match the AMV index exactly in both shape and amplitude. SI section 7Figures S35 and S36 show that whilst the model responses do capture some of the multidecadal variability in the observations, this is somewhat weaker and out-of-phase with the observed AMV. The latter part of the observed record (1960 onwards) is generally much better captured. This suggests that the weaker response seen in the model, compared to observations, may be due to the greater uncertainties in the earlier part of the observational record. Overall, there is some evidence that the modelled response to the AMV is weaker than the observed response, but the limited observational data makes it hard to be definitive.

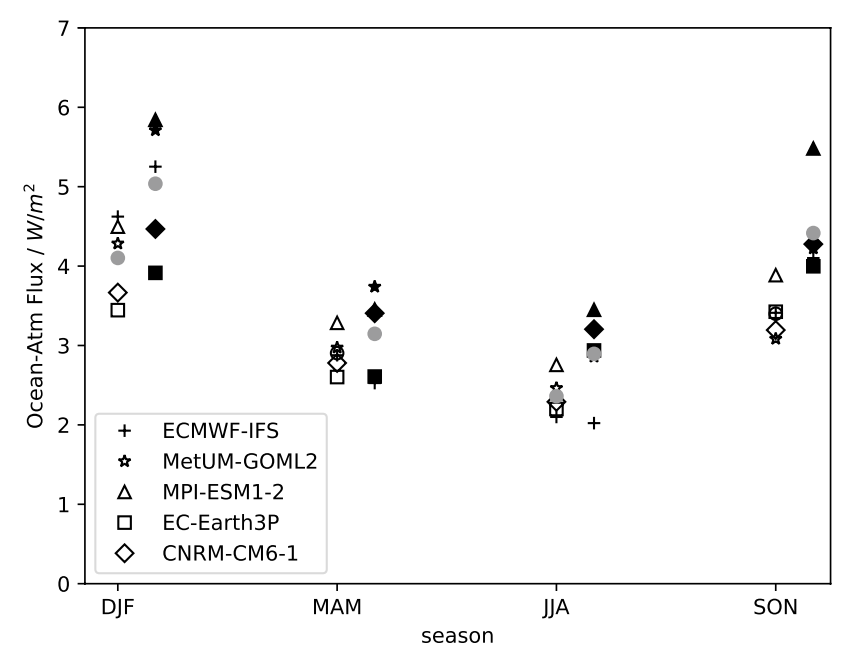

Fig. 18 Comparison of (open symbols, left) upward surface latent heat fluxes $\left(2 A M V^{+}-2 A M V^{-}\right)$and (black, right) net upward surface heat fluxes (latent, sensible, shortwave and longwave), both averaged over the AMV region (Fig. 1), for each season. Symbols show means over all ensemble members and resolutions for each model. Circle shows mean across all models. Grey filled circle denotes the model spread is significant from the ANOVA (e.g. $A_{e m}$ in section 3 ( eqn. 3)) 

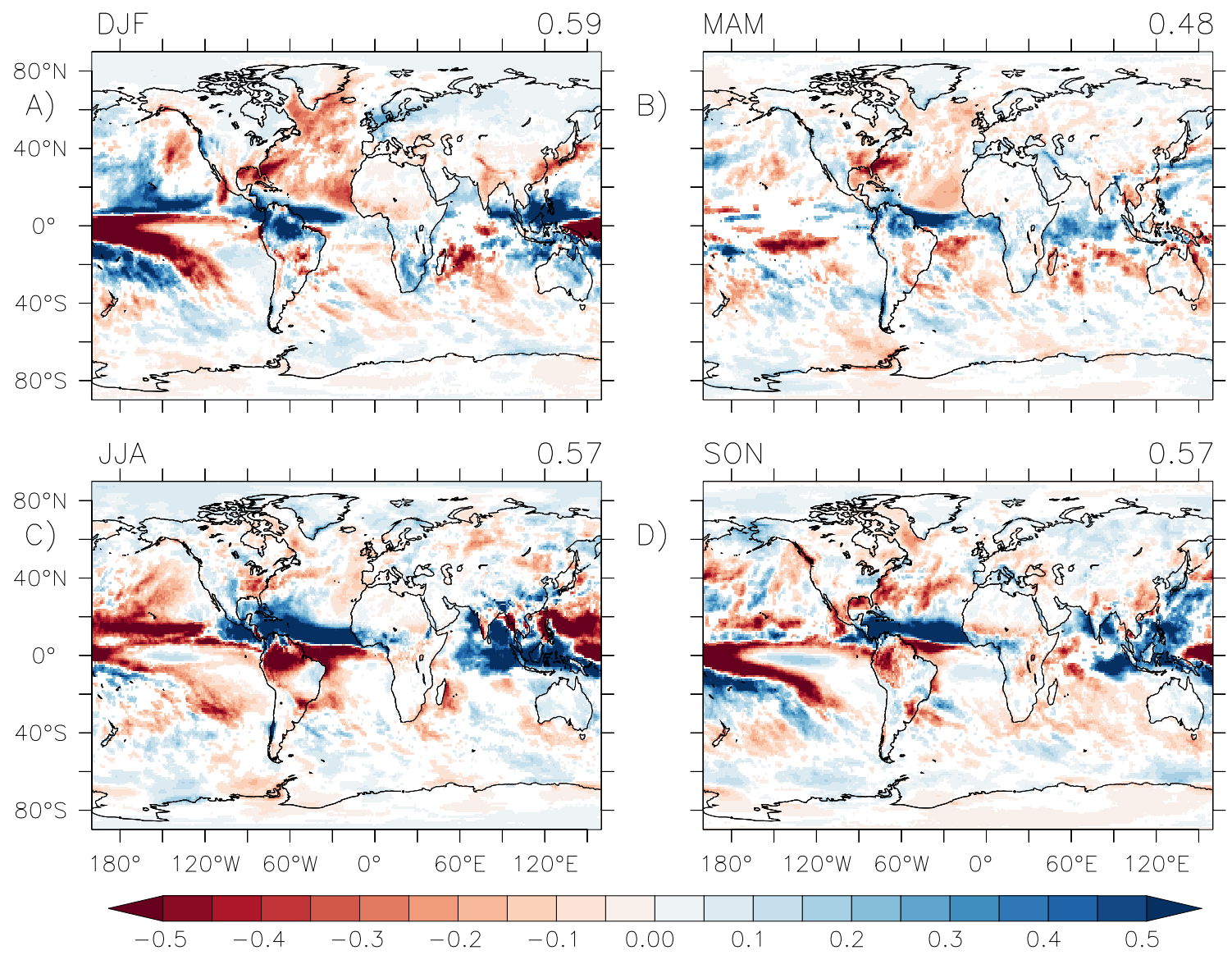

Fig. 19 As Fig. 2, but for precipitation-evaporation. Units: $\mathrm{mm} /$ day

Table 1 Atmosphere grid resolution in km for each model at low and high resolution configurations. The first number is the nominal resolution (derived from the model grid definition and threshold truncation (point 3) http://goo.gl/v1drZl (Appendix 2) or Klaver et al. (2020) supplementary) and the following number in brackets is the effective resolution (derived from the model grid's ability to resolve the KE spectra (see Klaver et al. 2020)

\begin{tabular}{lll}
\hline Model & Low resolution & High resolution \\
\hline CNRM-CM6-1 & $250(\geq 625)$ & $100(313)$ \\
EC-Earth & $100(351)$ & $50(238)$ \\
ECMWF-IFS & $100(253)$ & $50(185)$ \\
MetUM-GOML2 & $250(\geq 625)$ & $100(364)$ \\
MPIESM1.2 & $100(364)$ & $50(256)$ \\
\hline
\end{tabular}

\subsection{AMV forcing spread}

Whilst the AMV SST anomalies are consistently maintained across models (Fig. 9, Figure S11), the resulting net oceanatmosphere surface fluxes may differ across models. Examining this spread across models, the net surface latent heat fluxes released into the atmosphere over the North Atlantic AMV forcing region varies significantly across models in winter and summer, peaking in winter and autumn (Fig. 18). The spread increases when we consider the total net surface flux (Fig. 18). Hence, although the atmosphere in each model sees closely similar North Atlantic SST anomalies, there is a significant model spread in the resulting heat flux forcing of the atmosphere (perhaps due to a spread in conditions at the air-sea interface). This spread may arise from model formulation differences, or perhaps differences in the climatologies across the models (for example, the extent of sea ice cover over the Arctic). Such variation in forcing may be a significant factor in the model spread in the AMV climate response across models (Figs. 9-10). The model spread in surface air temperature (Fig. 9) over the Tropical Pacific appear to be partly related to this spread in AMV forcing (SI section 10-Figure S49) for part of the year. Ruprich-Robert et al. (2021) demonstrate that the latitude of the ITCZ varies across the model climatologies and that this explains a significant proportion of the spread in the Tropical Pacific response. 


\subsection{P-E}

The AMV drives global changes in the hydrological cycle via changes in precipitation (Fig. 4). The AMV also drives changes in surface evaporation (Fig. 5). These changes result in the net surface moisture fluxes (p-e: precipitation-evaporation) (Fig. 19). Whilst the AMV drives a reduction in precipitation across the US in summer (Fig. 4c) the net impact on p-e is positive for the central and western US; due to a widespread reduction in surface evaporation (Fig. 5). In contrast, the AMV drives a strong seasonal cycle of p-e over northern South America; with increased downward moisture fluxes in DJF and net upward fluxes in JJA. The enhanced South Asian monsoon (Fig. 4c) results in a mixed net downward moisture flux, the increased rainfall being balanced somewhat by enhanced evaporation. Over Europe, there is notable seasonality, with increased downward moisture flux in winter, and a drier summer and autumn.

\subsection{Summary}

In broad agreement with other AMV impact studies (Sutton and Hodson 2005; Hodson et al. 2009; Dong et al. 2006; Ruprich-Robert et al. 2018; Levine -et al. 2018), we can summarize the global response to the AMV as a northward shift in tropical precipitation (hence a northward shift of the ITCZ and perhaps the Hadley cell) together with an adjustment in the tropical Walker circulation. The Hadley cell changes are likely driven by the hemispheric imbalance in heating (e.g. Kang et al. 2008) and lead to global changes in precipitation following the displacement of the ITCZ. Latent heat release over the Tropical Atlantic may then drive changes in the tropical Walker circulation as shown by Kucharski et al. (2011). The resultant surface wind changes over the Equatorial Pacific interact with the ocean driving enhanced upwelling, via a Bjerknes feedback, leading to a widespread eastern and central Pacific cooling ( $\mathrm{Li}$ et al. 2016). This cooling increases subsidence and reduces convection over the East and Central Pacific, driving extratropical wavetrains (Scaife et al. 2017) leading to changes in extratropical circulation over the north Pacific and Atlantic. These large scale responses lead to widespread regional changes in temperature and circulation.

\section{Conclusions}

We have examined the global climate impact of the AMV in five coupled climate models, at two groups of atmospheric horizontal resolutions: low resolution (LR: 250-100 km) and high resolution (HR: 100-50 km) for each model. We have discussed the model mean climate response and where choice of model and resolution alters this response. Our key findings are:

- The AMV has a global-scale impact on climate, affecting global circulation, surface air temperature and rainfall. The positive AMV drives:

- warming over much of Eurasia, northern Africa and North and South America (Fig. 2). This is accompanied by some regional cooling over land: Alaska, northern sub-Saharan Africa and India. These changes are partly due to the advection of warm (or cold) air, partly due to changing shortwave fluxes due to changes in cloud cover. Outside the Atlantic, the AMV drives widespread cold SSTs, most notably a PDO-like cooling over the Central and eastern Pacific. This cooling is likely driven by enhanced ocean upwelling.

- a global shift in the hydrological cycle, characterized by a northward shift in the ITCZ over the Atlantic and Pacific and a displacement of the African Monsoon system, accompanied by reduced rainfall over the Tropical Pacific, and increased rainfall over Asia and the Maritime Continent (Fig. 4).

- global-scale changes in circulation, characterized by ascent over the Atlantic and descent over the Pacific (Fig. 3). The response peaks in summertime (JJA), but there are significant impacts on the Aleutian low during winter (DJF) and spring (MAM) - these latter drive anomalous cooling over Alaska and western Canada in winter (DJF).

These findings are consistent with previous AMV experiments with atmosphere-only models (Sutton and Hodson 2005, 2007; Hodson et al. 2009; Davini et al. 2015; Vigaud et al. 2018; Omrani et al. 2014, 2016) and also more recent studies with coupled models (Ruprich-Robert et al. 2017, 2018; Levine -et al. 2018; Monerie et al. 2019).

- There is a global multimodel-mean AMV response across multiple variables ( $\alpha_{e}$ - significant when compared to internal variability), but models disagree on the magnitude of this response in some regions $\left(A_{e m}\right)$-most notably in the Tropics (Figs. 9 and 10). Part of this model variation may arise from the differing atmosphere heat flux forcings that result from the same SST pattern forcing pattern (Fig. 18).

- We are generally unable to detect a change in the multimodel mean responses as model resolution is increased, although the extent of the northward displacement of the ITCZ has some sensitivity to resolution (Fig. 15), moving further north at higher resolution. There is also some 
evidence of an enhanced tropical Walker Circulation. This does not preclude the possibility that larger changes to the AMV response exist across a specific resolution threshold within our sample, or for resolutions greater than we have sampled here.

This study suggests that resolution (in the range we have sampled here) may not be a large source of uncertainty in experimental estimates of the large-scale impact of the AMV. Model variation is likely to be a more significant source of uncertainty. Resolution may play a greater role for smaller scale processes or extremes, such as hurricanes or temperature extremes. Future studies analysis will examine these impacts in these experiments. Given the widespread nature of the impacts of the AMV seen in this study, a better understanding of these model uncertainties, combined with good estimates of the future evolution of the AMV are crucial to predict near-term global climate changes. Further future analysis of the full CMIP6 DCPP-C AMV experiment ensemble will enhance our understanding and ability to do this.

\section{A Analysis of Variance (ANOVA)}

In this section we outline the basis for Analysis of Variance (ANOVA) see Storch and Zwiers (1999, p117), Zwiers (1996) or Wilks (2019) for detailed explanations). ANOVA aims to decompose the total variance of a dataset into contributions from different factors. The significance of each contribution can then be assessed.

Consider a multi-model ensemble experiment with $(m=1 . . M)$ models and $(e=1 . . E)$ experiments, where each experiment was performed $(j=1 . . J)$ times. ${ }^{1}$ Suppose we wish to examine the factors influencing Mean Sea Level Pressure (MSLP) in this ensemble. Assuming the models uses a common spatial grid, we can define MSLP at a grid point across all experiments $(e)$, models $(m)$ and ensemble members $(j)$ to be $X_{e m j}$. We can then express $X_{e m j}$ as a linear combination of factors:

$X_{e m j}=\mu+\alpha_{e}+\beta_{m}+\gamma_{e m}+\epsilon_{e m j}$

Here, $\mu$ is the average over all experiments, models and ensemble members: number of ensemble members, $j$, but the subsequent statistical tests will no longer be exact. See (See Storch and Zwiers 1999, p. 178).
$\mu=\frac{1}{E M J} \sum_{e m j} X_{e m j}$

$\alpha_{e}$ is the part of MSLP that changes between experiment, but does not change between ensemble members or models. We could consider this the true experimental response (about which individual model responses will cluster). Because of the definition of $\mu(6), \alpha_{e}$ is constrained to satisfy:

$\sum_{e} \alpha_{e}=0$

$\beta_{m}$ is the part of MSLP that changes between models, but does not change between experiments or ensemble members. In other words, it is the model bias of a given model $m$. Again, $\beta_{m}$ is constrained in the same manner as $\alpha_{e}$ :

$\sum_{m} \beta_{m}=0$

$\gamma_{e m}$ is often called the interaction term-it accounts for the across-experiment differences between the ensemblemeans, once the model biases $\left(\beta_{m}\right)$ have been accounted for. $\gamma_{e m}$ is similarly constrained by the definitions of $\mu, \alpha_{e}$ and $\beta_{m}$ to satisfy:

$\sum_{e} \gamma_{e m}=\sum_{m} \gamma_{e m}=0$

Finally, $\epsilon_{e m j}$ describes the residual noise. $\epsilon_{e m j}$ is assumed to be independent and normally distributed with a zero mean and a variance of $\sigma_{\epsilon}^{2}$, e.g. $\epsilon_{e m j} \sim N\left(0, \sigma_{\epsilon}^{2}\right)$. Having proposed a linear statistical model for this variable, we can form hypotheses and construct tests. For example, is there a significant model bias between the models? In other words, do the models have a spread of MSLP climatologies that is detectable above the internal variability, $\epsilon_{e m j}$ ? We can re-frame the question as: is $\sum_{m} \beta_{m}^{2}>0$ ?

To answer this question we first define the Total Sum of Squares, TSS

$T S S=\sum_{e m j}\left(X_{e m j}-X_{\circ \circ \circ}\right)^{2}$

Where, o implies a mean over that index-for example:

$X_{\text {omj }}=\frac{1}{E} \sum_{e} X_{e m j}$

On close inspection, as the noise term $\epsilon_{e m j}$ is independently distributed, the cross terms between different $j$ vanish, hence TSS can be decomposed as follows:

$T S S=S S \alpha+S S \beta+S S \gamma+S S \epsilon$

where 


$$
\begin{aligned}
& S S \alpha=\sum_{e m j}\left(X_{e \circ \circ}-X_{\circ \circ \circ}\right)^{2} \\
& S S \beta=\sum_{e m j}\left(X_{\circ m \circ}-X_{\circ \circ \circ}\right)^{2} \\
& S S \gamma=\sum_{e m j}\left(X_{e m \circ}-X_{e \circ \circ}-X_{\circ m \circ}+X_{\circ \circ \circ}\right)^{2} \\
& S S \epsilon=\sum_{e m j}\left(X_{e m j}-X_{e m \circ}\right)^{2}
\end{aligned}
$$

This is simply the familiar idea that the total variance is just the sum of individual sources of variance. We can then construct unbiased estimators of the terms on the right hand side of Eq. 5. Consequently, it can be shown (e.g. Storch and Zwiers 1999) that $S S \beta$ is an unbiased estimator of:

$E J \sum_{m} \beta_{m}^{2}+(M-1) \sigma_{\epsilon}^{2}$

Similarly, it can be shown that $S S \epsilon$ is an unbiased estimator of

$E M(J-1) \sigma_{\epsilon}^{2}$

Therefore the ratio

$$
\frac{S S \beta /(M-1)}{S S \epsilon / E M(J-1)}
$$

is an unbiased estimator of

$\frac{\frac{E J}{M-1} \sum_{m} \beta_{m}^{2}+\sigma_{\epsilon}^{2}}{\sigma_{\epsilon}^{2}}$

If $\sum_{m} \beta_{m}^{2}>0$ then this expression will be greater than 1. Formally we can then pose a null hypothesis $H_{0}$ and an alternative hypothesis $H_{1}$ :

$$
\begin{aligned}
& H_{0}: \sum_{m} \beta_{m}^{2}=0 \\
& H_{1}: \sum_{m} \beta_{m}^{2} \neq 0
\end{aligned}
$$

In other words, if at least one of $\beta_{m}$ is not equal to zero then we can reject the null hypothesis $H_{0}$. An F-test can be used to test $H_{0}$ by assessing whether the $F$-statistic (10) is significantly greater than 1 (using the F-distribution $F_{M-1, E M(J-1)}$ ). A significant result (e.g. $p<0.05$ ) implies that the factor represented by $\beta_{m}$, in this case model bias, has a detectable effect on MSLP in this multi-model ensemble experiment. Comparing $\sum_{m} \beta_{m}^{2}$ to $\sigma_{\epsilon}^{2}$ in this way, allows us to assess whether the effects associated with $\beta_{m}$ are greater than the noise, $\epsilon_{e m j}$. Similar estimators to (10), and hence similar tests, can be found for $\alpha_{e}$ and $\gamma_{e m}$.
We can also estimate the size of the effect of a given factor on $X_{e m j}$ in (5) by computing the fraction of the variance explained (FVE). Examination of (8) and (9) shows that:

$S S \beta-\frac{M-1}{E M(J-1)} S S \epsilon=E J \sum_{m} \beta_{m}^{2}$

is an unbiased estimator of the variance of $\beta_{m}$.

Therefore:

$F V E_{\beta}=\frac{S S \beta-\frac{M-1}{E M(J-1)} S S \epsilon}{T S S}$

$F V E_{\beta}$ is (an unbiased estimate of) the fraction of the total variance (TSS), explained by $\beta_{m}$ (see 7). Similar expressions can also be found for $\alpha_{e}$ and $\gamma_{e m}$.

Furthermore, it can be shown that ANOVA is a more general form of the t-test. For example, for the simpler case of one factor (e.g. one-way ANOVA) (5) becomes,

$X_{m j}=\mu+\beta_{m}+\epsilon_{m j}$

For the case of only two models ( $\mathrm{M}=2$-i.e. two samples) the F-statistic (10) for $\beta_{m}$ is exactly equal to the square of the corresponding two-sample t-statistic, and it can be shown (by integration) that the cumulative distributions of $t_{n}$ and $F_{1, n}$ are identical. Hence, one-way ANOVA with two treatments $(\mathrm{M}=2)$ is a two-sample t-test. Equally, we can extend this model to:

$X_{m j}=\mu+\beta_{m}+C_{j}+\epsilon_{m j}$

where $C_{j}$ is a factor that is the same for each $m$, but varies with ensemble member $j$. For $M=2$, this reduces to a paired t-test - the presence of $C_{j}$ reduces the estimate of the noise variance $\left(\sigma_{\epsilon}^{2}\right)$, which reduces the denominator in (10) leading to a larger F-statistic. A paired t-test similarly eliminates $C_{j}$ by computing pair differences between the two samples, which results in a reduced denominator in the corresponding $\mathrm{t}$-statistic, and hence a more sensitive test. In both cases a source of variance is being removed to compare the remaining variance of interest with a better estimate of the noise.

We can extend the statistical model (5) to include more factors. In this paper, we consider consider the extra factor of resolution, and hence $X_{e m r j}$, where $r$ is resolution. (5) can then be extended to include all possible interactions between these factors, and hence:

$X_{e m r j}=\mu+\alpha_{e}+\beta_{m}+\gamma_{r}+A_{e m}+G_{e r}+Z_{m r}+W_{e m r}+\epsilon_{e m r j}$

Here, $A_{e m}$ replaces $\gamma_{e m} \cdot \gamma_{r}$ represents the climatology changes that occur averaged across all models when resolution is changed, irrespective of the experiment. $G_{e r}$ represents how the experimental response changes when resolution is changed—a key question for this paper. $Z_{m r}$ represents 
how the spread of model climatologies changes when resolution is changed, irrespective of the experiment. $W_{e m r}$ represents how the model spread between experiments changes when resolution is changed. In this way, we account for all possible sources of variance, which refines and reduces the estimate of the noise $\epsilon_{e m r j}$, allowing us to detect smaller influences of the various factors than would otherwise be the case.

Acknowledgements The Authors would like to acknowledge the use of the UKRI funded JASMIN data analysis facility which was essential to the analysis and storage of PRIMAVERA project data. Ongoing curation of project data has been supported by the IS-ENES3 project that has received funding from the European Union' Horizon 2020 research and innovation programme under Grant Agreement No. 824084. Authors DH, PM, JS, PD, YRR, CDR acknowledge funding from the PRIMAVERA project (www.primavera-h2020.eu), funded by the European Union's Horizon 2020 programme under Grant Agreement 641727. PM was supported by U.K.-China Research and Innovation Partnership Fund through the Met Office Climate Science for Service Partnership (CSSP) China as part of the Newton Fund. PD thanks ECMWF for providing computing time in the framework of the special projects SPITDAVI. YRR was funded by the European Union's Horizon 2020 Research and Inovation Programme in the framework of the Marie Skłodowska-Curie grant INADEC (Grant Agreement 80015400). Author DH would like to thank Nick Klingaman and Linda Hirons for their extensive help with the MetUM-GOML model. This article was written with support (DH) from National Environmental Research Council (NERC) national capability grant for the North Atlantic Climate System: Integrated study (ACSIS) program (Grants NE/N018001/1, NE/N018044/1, NE/N018028/1, and NE/N018052/1). MMR is supported by a Juan de la Cierva Incorporacion research contract of MICINN (Spain). The authors wish to acknowledge use of the Ferret program for analysis and graphics in this paper. Ferret is a product of NOAA's Pacific Marine Environmental Laboratory. (Information is available at http://ferret.pmel.noaa.gov/Ferret/) and also the CF-python analysis package http://ncas-cms.github.io/cf-python/. Assembly of MetUM-GOML and development of MC-KPP was supported by the National Centre for Atmospheric Science and led by Dr. Nicholas Klingaman. The authors would also like to thank the three anonymous reviewers whose comments contributed to a much improved final manuscript.

Funding Funding was as set out in then Acknowledgements.

\section{Declarations}

Conflict of interest The authors declare that they have no conflict of interest.

Availability of data and code The data and code used in this paper are available at https://doi.org/10.5281/zenodo.5884227.

Open Access This article is licensed under a Creative Commons Attribution 4.0 International License, which permits use, sharing, adaptation, distribution and reproduction in any medium or format, as long as you give appropriate credit to the original author(s) and the source, provide a link to the Creative Commons licence, and indicate if changes were made. The images or other third party material in this article are included in the article's Creative Commons licence, unless indicated otherwise in a credit line to the material. If material is not included in the article's Creative Commons licence and your intended use is not permitted by statutory regulation or exceeds the permitted use, you will need to obtain permission directly from the copyright holder. To view a copy of this licence, visit http://creativecommons.org/licenses/by/4.0/.

\section{References}

Allan R, Ansell T (2006) A new globally complete monthly historical Gridded Mean Sea Level Pressure Dataset (HadSLP2): 18502004. J Clim 19(22):5816-5842. https://doi.org/10.1175/jcli3 937.1

Balsamo G, Beljaars A, Scipal K, Viterbo P, van den Hurk B, Hirschi M, Betts AK (2009) A revised hydrology for the ECMWF model: verification from field site to terrestrial water storage and impact in the integrated forecast system. J Hydrometeorol 10(3):623643. https://doi.org/10.1175/2008JHM1068.1

Berckmans J, Woollings T, Demory ME, Vidale PL, Roberts M (2013) Atmospheric blocking in a high resolution climate model: influences of mean state, orography and eddy forcing. Atmos Sci Lett 14(1):34-40. https://doi.org/10.1002/asl2.412

Birkel SD, Mayewski PA, Maasch KA, Kurbatov AV, Lyon B (2018) Evidence for a volcanic underpinning of the Atlantic multidecadal oscillation. NPJ Clim Atmos Sci 1(1):1-7. https://doi.org/ 10.1038/s41612-018-0036-6. https://www.nature.com/articles/ s41612-018-0036-6, number: 1 Publisher: Nature Publishing Group

Bjerknes J (1969) Atmospheric teleconnections from the equatorial pacific. Monthly Weather Rev 97(3):163-172. https://doi.org/10. 1175/1520-0493(1969)097<0163:ATFTEP>2.3.CO;2. https:// journals.ametsoc.org/view/journals/mwre/97/3/1520-0493_ 1969_097_0163_atftep_2_3_co_2.xml, publisher: American Meteorological Society Section: Monthly Weather Review

Boer GJ, Smith DM, Cassou C, Doblas-Reyes F, Danabasoglu G, Kirtman B, Kushnir Y, Kimoto M, Meehl GA, Msadek R, Mueller WA, Taylor KE, Zwiers F, Rixen M, Ruprich-Robert Y, Eade R (2016) The decadal climate prediction project (DCPP) contribution to CMIP6. Geosci Model Dev 9(10):3751-3777. https://doi. org/10.5194/gmd-9-3751-2016. https://www.geosci-model-dev. net/9/3751/2016/

Booth BBB, Dunstone NJ, Halloran PR, Andrews T, Bellouin N (2012) Aerosols implicated as a prime driver of twentieth-century North Atlantic climate variability. Nature 484(7393):228-232. https:// doi.org/10.1038/nature10946

Bouillon S, Morales Maqueda MA, Legat V, Fichefet T (2009) An elastic-viscous-plastic sea ice model formulated on Arakawa B and C grids. Ocean Model 27(3):174-184. https://doi.org/10. 1016/j.ocemod.2009.01.004. http://www.sciencedirect.com/scien ce/article/pii/S1463500309000043

Buckley MW, Marshall J (2016) Observations, inferences, and mechanisms of the Atlantic Meridional Overturning Circulation: a review. Rev Geophys 54(1):5-63. https://doi.org/10.1002/2015R G000493

Cassou C, Terray L, Hurrell JW, Deser C (2004) North Atlantic Winter climate regimes: spatial asymmetry, stationarity with time, and oceanic forcing. J Clim 17(5):1055-1068. https://doi.org/10. 1175/1520-0442(2004)017<3C1055:nawcrs >3E2.0.co;2

Christensen OB, Kjellström E (2020) Partitioning uncertainty components of mean climate and climate change in a large ensemble of European regional climate model projections. Clim Dyn 54(9):4293-4308. https://doi.org/10.1007/s00382-020-05229-y

Clement A, Bellomo K, Murphy LN, Cane MA, Mauritsen T, Rädel G, Stevens B (2015) The Atlantic Multidecadal Oscillation without a role for ocean circulation. Science 350(6258):320-324. https:// doi.org/10.1126/science.aab3980. https://www.science.org/doi/ 
full/10.1126/science.aab3980, publisher: American Association for the Advancement of Science

Craig A, Valcke S, Coquart L (2017) Development and performance of a new version of the OASIS coupler, OASIS3-MCT_3.0. Geosci Model Dev 10(9):3297-3308. https://doi.org/10.5194/gmd-103297-2017. https://www.geosci-model-dev.net/10/3297/2017/

Czaja A, Frankignoul C, Minobe S, Vannière B (2019) Simulating the midlatitude atmospheric circulation: what might we gain from high-resolution modeling of air-sea interactions? Curr Clim Change Rep 5(4):390-406. https://doi.org/10.1007/ s40641-019-00148-5

Davini P, Hardenberg J, Corti S (2015) Tropical origin for the impacts of the Atlantic Multidecadal Variability on the Euro-Atlantic climate. Environ Res Lett 10(9):094010. https://doi.org/10.1088/ 1748-9326/10/9/094010. publisher: IOP Publishing

Decharme B, Delire C, Minvielle M, Colin J, Vergnes JP, Alias A, Saint-Martin D, Séférian R, Sénési S, Voldoire A (2019) Recent changes in the ISBA-CTRIP land surface system for use in the CNRM-CM6 climate model and in global off-line hydrological applications. J Adv Model Earth Syst 11(5):1207-1252. https:// doi.org/10.1029/2018MS001545

Delworth T, Manabe S, Stouffer RJ (1993) Interdecadal variations of the thermohaline circulation in a coupled ocean-atmosphere model. J Clim 6(11):1993-2011. https://doi.org/10.1175/15200442(1993)006<1993:IVOTTC>2.0.CO;2. https://journals. ametsoc.org/jcli/article/6/11/1993/36096/Interdecadal-Varia tions-of-the-Thermohaline, publisher: American Meteorological Society

Demory ME, Vidale PL, Roberts MJ, Berrisford P, Strachan J, Schiemann R, Mizielinski MS (2014) The role of horizontal resolution in simulating drivers of the global hydrological cycle. Clim Dyn 42(7):2201-2225. https://doi.org/10.1007/s00382-013-1924-4

Deser C, Alexander MA, Xie SP, Phillips AS (2010) Sea surface temperature variability: patterns and mechanisms. Ann Rev Mar Sci 2(1):115-143. https://doi.org/10.1146/annur ev-marine-120408-151453

Dong B, Sutton RT (2007) Enhancement of ENSO Variability by a weakened Atlantic thermohaline circulation in a coupled GCM. J Clim 20(19):4920-4939. https://doi.org/10.1175/jcli4284.1

Dong B, Sutton RT, Scaife AA (2006) Multidecadal modulation of El Niño-Southern Oscillation (ENSO) variance by Atlantic Ocean sea surface temperatures. Geophys Res Lett 33(8). https://doi. org/10.1029/2006GL025766

Déqué M, Dreveton C, Braun A, Cariolle D (1994) The ARPEGE/ IFS atmosphere model: a contribution to the French community climate modelling. Clim Dyn 10(4):249-266. https://doi.org/10. 1007/BF00208992

Elsbury D, Peings Y, Saint-Martin D, Douville H, Magnusdottir G (2019) The atmospheric response to positive IPV, positive AMV, and their combination in boreal winter. J Clim 32(14):41934213. https://doi.org/10.1175/JCLI-D-18-0422.1. https://journ als.ametsoc.org/jcli/article/32/14/4193/343959/The-Atmos pheric-Response-to-Positive-IPV-Positive, publisher: American Meteorological Society

Enfield DB, Mestas-Nuñez AM, Trimble PJ (2001) The Atlantic multidecadal oscillation and its relation to rainfall and river flows in the continental U.S. Geophys Res Lett 28(10):2077-2080. https://doi.org/10.1029/2000GL012745

England MH, McGregor S, Spence P, Meehl GA, Timmermann A, Cai W, Gupta AS, McPhaden MJ, Purich A, Santoso A (2014) Recent intensification of wind-driven circulation in the Pacific and the ongoing warming hiatus. Nat Clim Chang 4(3):222227. https://doi.org/10.1038/nclimate2106. https://www. nature.com/articles/nclimate2106, bandiera_abtest: a Cg_type: Nature Research Journals Number: 3 Primary_atype: Research Publisher: Nature Publishing Group Subject_term: Physical
oceanography;Projection and prediction Subject_term_id: physical-oceanography;projection-and-prediction

Fichefet T, Maqueda MAM (1997) Sensitivity of a global sea ice model to the treatment of ice thermodynamics and dynamics. J Geophys Res Oceans 102(C6):12609-12646. https://doi.org/10.1029/ 97JC00480

Folland CK, Palmer TN, Parker DE (1986) Sahel rainfall and worldwide sea temperatures, 1901-85. Nature 320(6063):602-607. https://doi.org/10.1038/320602a0

Folland CK, Colman AW, Rowell DP, Davey MK (2001) Predictability of Northeast Brazil Rainfall and Real-Time Forecast Skill, 1987-98. Journal of Climate 14(9):1937-1958. https://doi.org/ 10.1175/1520-0442(2001)014\%3C1937:ponbra\%3E2.0.co;2

Fosser G, Khodayar S, Berg P (2015) Benefit of convection permitting climate model simulations in the representation of convective precipitation. Clim Dyn 44(1):45-60. https://doi.org/10.1007/ s00382-014-2242-1

Frierson DMW, Hwang YT, Fučkar NS, Seager R, Kang SM, Donohoe A, Maroon EA, Liu X, Battisti DS (2013) Contribution of ocean overturning circulation to tropical rainfall peak in the Northern Hemisphere. Nat Geosci 6(11):940-944. https://doi.org/10.1038/ ngeo1987. https://www.nature.com/articles/ngeo1987, number: 11 Publisher: Nature Publishing Group

Gastineau G, Frankignoul C (2014) Influence of the North Atlantic SST variability on the atmospheric circulation during the twentieth century. J Clim 28(4):1396-1416. https://doi.org/10.1175/ jcli-d-14-00424.1

Gent PR, Mcwilliams JC (1990) Isopycnal mixing in ocean circulation models. J Phys Oceanogr 20(1):150-155. https://doi.org/10. 1175/1520-0485(1990)020\%3C0150:imiocm\%3E2.0.co;2

Gill AE (1980) Some simple solutions for heat-induced tropical circulation. Q J R Meteorol Soc 106(449):447-462. https://doi.org/ 10.1002/qj.49710644905

Goldenberg SB, Landsea CW, Mestas-Nuñez AM, Gray WM (2001) The recent increase in atlantic hurricane activity: causes and implications. Science 293(5529):474-479. https://doi.org/10. 1126/science. 1060040

Haarsma R, Acosta M, Bakhshi R, Bretonnière PA, Caron LP, Castrillo M, Corti S, Davini P, Exarchou E, Fabiano F, Fladrich U, Fuentes Franco R, García-Serrano J, Hardenberg Jv, Koenigk T, Levine X, Meccia VL, Noije Tv, Oord Gvd, Palmeiro FM, Rodrigo M, Ruprich-Robert Y, Sager PL, Tourigny E, Wang S, Weele Mv, Wyser K (2020) HighResMIP versions of EC-Earth: EC-Earth3P and EC-Earth3P-HR - description, model computational performance and basic validation. Geosci Model Dev 13(8):3507-3527. https://doi.org/10.5194/gmd-13-3507-2020. https://gmd.copernicus.org/articles/13/3507/2020/. publisher: Copernicus $\mathrm{GmbH}$

Hazeleger W, Bintanja R (2012) Studies with the EC-Earth seamless earth system prediction model. Clim Dyn 39(11):2609-2610. https://doi.org/10.1007/s00382-012-1577-8

He J, Kirtman B, Soden BJ, Vecchi GA, Zhang H, Winton M (2018) Impact of Ocean Eddy resolution on the sensitivity of precipitation to CO2 increase. Geophys Res Lett 45(14):7194-7203. https://doi.org/10.1029/2018GL078235

Hewitt HT, Roberts MJ, Hyder P, Graham T, Rae J, Belcher SE, Bourdallé-Badie R, Copsey D, Coward A, Guiavarch C, Harris C, Hill R, Hirschi JJM, Madec G, Mizielinski MS, Neininger E, New AL, Rioual JC, Sinha B, Storkey D, Shelly A, Thorpe L, Wood RA (2016) The impact of resolving the Rossby radius at mid-latitudes in the ocean: results from a high-resolution version of the Met Office GC2 coupled model. Geosci Model Dev 9(10):3655-3670. https://doi.org/10.5194/gmd-9-3655-2016. https://gmd.copernicus.org/articles/9/3655/2016/gmd-9-36552016.html, publisher: Copernicus $\mathrm{GmbH}$ 
Hewitt HT, Bell MJ, Chassignet EP, Czaja A, Ferreira D, Griffies SM, Hyder P, McClean JL, New AL, Roberts MJ (2017) Will highresolution global ocean models benefit coupled predictions on short-range to climate timescales? Ocean Model 120:120-136. https://doi.org/10.1016/j.ocemod.2017.11.002. https://www.scien cedirect.com/science/article/pii/S1463500317301774

Hirons LC, Klingaman NP, Woolnough SJ (2015) MetUM-GOML1: a near-globally coupled atmosphere-ocean-mixed-layer model. Geoscientific Model Development 8(2):363-379, https://doi.org/ 10.5194/gmd-8-363-2015. https://www.geosci-model-dev.net/8/ $363 / 2015 /$

Hodson DLR, Sutton RT (2008) Exploring multi-model atmospheric GCM ensembles with ANOVA. Clim Dyn 31(7):973-986. https://doi.org/10.1007/s00382-008-0372-z

Hodson DLR, Sutton RT (2012) The impact of resolution on the adjustment and decadal variability of the Atlantic meridional overturning circulation in a coupled climate model. Clim Dyn. https://doi. org/10.1007/s00382-012-1309-0

Hodson DLR, Sutton RT, Cassou C, Keenlyside N, Okumura Y, Zhou T (2009) Climate impacts of recent multidecadal changes in Atlantic Ocean Sea Surface Temperature: a multimodel comparison. Clim Dyn. https://doi.org/10.1007/s00382-009-0571-2

Hodson DLR, Robson JI, Sutton RT (2014) An Anatomy of the Cooling of the North Atlantic Ocean in the 1960s and 1970s. J Clim 27(21):8229-8243. https://doi.org/10.1175/JCLI-D-14-00301.1. https://journals.ametsoc.org/jcli/article/27/21/8229/33482/AnAnatomy-of-the-Cooling-of-the-North-Atlantic, publisher: American Meteorological Society

Hoerling M, Hurrell J, Eischeid J, Phillips A (2006) Detection and Attribution of Twentieth-Century Northern and Southern African Rainfall Change. J Clim 19(16):3989-4008. https://doi.org/10. $1175 /$ jcli3842.1

Huang B, Banzon VF, Freeman E, Lawrimore J, Liu W, Peterson TC, Smith TM, Thorne PW, Woodruff SD, Zhang HM (2015) Extended Reconstructed Sea Surface Temperature Version 4 (ERSST.v4). Part I: Upgrades and Intercomparisons. Journal of Climate 28(3):911-930, https://doi.org/10.1175/JCLI-D14-00006.1, https://journals.ametsoc.org/jcli/article/28/3/911/ 106716/Extended-Reconstructed-Sea-Surface-Temperature, publisher: American Meteorological Society

Hurlburt HE, Metzger EJ, Hogan PJ, Tilburg CE, Shriver JF (2008) Steering of upper ocean currents and fronts by the topographically constrained abyssal circulation. Dynamics of Atmospheres and Oceans 45(3):102-134, https://doi.org/10.1016/j.dynatmoce. 2008.06.003, https://www.sciencedirect.com/science/article/pii/ S0377026508000328

Jackson LC, Roberts MJ, Hewitt HT, Iovino D, Koenigk T, Meccia VL, Roberts CD, Ruprich-Robert Y, Wood RA (2020) Impact of ocean resolution and mean state on the rate of AMOC weakening. Clim Dyn 55(7):1711-1732. https://doi.org/10.1007/s00382020-05345-9, https://doi.org/10.1007/s00382-020-05345-9

Jung T, Miller MJ, Palmer TN, Towers P, Wedi N, Achuthavarier D, Adams JM, Altshuler EL, Cash BA, Kinter JL, Marx L, Stan C, Hodges KI (2012) High-Resolution Global Climate Simulations with the ECMWF Model in Project Athena: Experimental Design, Model Climate, and Seasonal Forecast Skill. J Clim 25(9):3155-3172. https://doi.org/10.1175/JCLI-D-11-00265.1. https://journals.ametsoc.org/view/journals/clim/25/9/jcli-d-1100265.1.xml, publisher: American Meteorological Society Section: Journal of Climate

Jungclaus JH, Fischer N, Haak H, Lohmann K, Marotzke J, Matei D, Mikolajewicz U, Notz D, Storch JS (2013) Characteristics of the ocean simulations in the Max Planck Institute Ocean Model (MPIOM) the ocean component of the MPI-Earth system model. J Adv Model Earth Syst 5(2):422-446. https://doi.org/10.1002/ jame.20023
Kajtar JB, Santoso A, McGregor S, England MH, Baillie Z (2018) Model under-representation of decadal Pacific trade wind trends and its link to tropical Atlantic bias. Clim Dyn 50(3):1471-1484. https://doi.org/10.1007/s00382-017-3699-5

Kang SM, Held IM, Frierson DMW, Zhao M (2008) The response of the ITCZ to extratropical thermal forcing: idealized slab-ocean experiments with a GCM. J Clim 21(14):3521-3532. https://doi. org/10.1175/2007jcli2146.1

Kerr RA (2000) A north atlantic climate pacemaker for the centuries. Science (New York, NY) 288(5473):1984-1985. https://doi.org/ 10.1126/science.288.5473.1984

Klaver R, Haarsma R, Vidale PL, Hazeleger W (2020) Effective resolution in high resolution global atmospheric models for climate studies. Atmos Sci Lett 21(4). https://doi.org/10.1002/asl.952

Knight JR, Folland CK, Scaife AA (2006) Climate impacts of the Atlantic Multidecadal Oscillation. Geophys Res Lett 33(17):L17706+. https://doi.org/10.1029/2006g1026242

Knutti R, Masson D, Gettelman A (2013) Climate model genealogy: generation CMIP5 and how we got there. Geophys Res Lett 40(6):1194-1199. https://doi.org/10.1002/grl.50256

Kucharski F, Kang IS, Farneti R, Feudale L (2011) Tropical Pacific response to 20th century Atlantic warming. Geophys Res Lett 38(3). https://doi.org/10.1029/2010GL046248

Kucharski F, Ikram F, Molteni F, Farneti R, Kang IS, No HH, King MP, Giuliani G, Mogensen K (2016) Atlantic forcing of Pacific decadal variability. Clim Dyn 46(7):2337-2351. https://doi.org/ 10.1007/s00382-015-2705-z

Kucharski F, Parvin A, Rodriguez-Fonseca B, Farneti R, Martin-Rey M, Polo I, Mohino E, Losada T, Mechoso CR (2016b) The Teleconnection of the Tropical Atlantic to Indo-Pacific Sea Surface Temperatures on Inter-Annual to Centennial Time Scales: a review of recent findings. Atmosphere 7(2):29. https://doi.org/ 10.3390/atmos7020029. https://www.mdpi.com/2073-4433/7/2/ 29, number: 2 Publisher: Multidisciplinary Digital Publishing Institute

Kwon YO, Seo H, Ummenhofer CC, Joyce TM (2020) Impact of multidecadal variability in Atlantic SST on winter atmospheric blocking. J Clim 33(3):867-892. https://doi.org/10.1175/ JCLI-D-19-0324.1

Lean JL (2018) Estimating Solar Irradiance since 850 CE. Earth Space Sci 5(4):133-149. https://doi.org/10.1002/2017EA000357

Levine AFZ, Frierson DMW, McPhaden MJ (2018) AMO forcing of multidecadal pacific ITCZ variability. Journal of Clim 31(14):5749-5764, https://doi.org/10.1175/JCLI-D-17-0810.1. https://journals.ametsoc.org/jcli/article/31/14/5749/93377/AMOForcing-of-Multidecadal-Pacific-ITCZ, publisher: American Meteorological Society

Li X, Holland DM, Gerber EP, Yoo C (2014) Impacts of the north and tropical Atlantic Ocean on the Antarctic Peninsula and sea ice. Nature 505(7484):538-542, https://doi.org/10.1038/natur e12945. https://www.nature.com/articles/nature12945, bandiera_abtest: a Cg_type: Nature Research Journals Number: 7484 Primary_atype: Research Publisher: Nature Publishing Group Subject_term: Atmospheric dynamics;Attribution;Climate and Earth system modelling;Projection and prediction Subject_term_ id: atmospheric-dynamics;attribution;climate-and-earth-systemmodelling;projection-and-prediction

Li X, Xie SP, Gille ST, Yoo C (2016) Atlantic-induced pan-tropical climate change over the past three decades. Nat Clim Chang 6(3):275-279. https://doi.org/10.1038/nclimate2840. https:// www.nature.com/articles/nclimate2840, number: 3 Publisher: Nature Publishing Group

Livezey RE, Chen WY (1983) Statistical Field Significance and its Determination by Monte Carlo Techniques. Monthly Weather Rev 111(1):46-59. https://doi.org/10.1175/1520-0493(1983) $111<0046$ :SFSAID>2.0.CO;2. https://journals.ametsoc.org/ 
view/journals/mwre/111/1/1520-0493_1983_111_0046_sfsaid_ 2_0_co_2.xml, publisher: American Meteorological Society Section: Monthly Weather Review

Lyu K, Yu JY (2017) Climate impacts of the Atlantic Multidecadal Oscillation simulated in the CMIP5 models: A re-evaluation based on a revised index. Geophys Res Lett 44(8):3867-3876. https://doi.org/10.1002/2017GL072681

Lyu K, Yu JY, Paek H (2017) The Influences of the Atlantic Multidecadal Oscillation on the Mean Strength of the North Pacific subtropical high during boreal winter. J Clim 30(1):411-426. https://doi.org/10.1175/JCLI-D-16-0525.1. https://journals.amets oc.org/view/journals/clim/30/1/jcli-d-16-0525.1.xml, publisher: American Meteorological Society Section: Journal of Climate

Madec G, Bourdallé-Badie R, Bouttier PA, Bricaud C, Bruciaferri D, Calvert D, Chanut J, Clementi E, Coward A, Delrosso D, Ethé C, Flavoni S, Graham T, Harle J, Iovino D, Lea D, Lévy C, Lovato T, Martin N, Masson S, Mocavero S, Paul J, Rousset C, Storkey D, Storto A, Vancoppenolle M (2017) NEMO ocean engine. https://doi.org/10.5281/zenodo.1472492. https://zenodo. org/record/1472492\#.XkPvkeGnzRY

Marzocchi A, Hirschi JJM, Holliday NP, Cunningham SA, Blaker AT, Coward AC (2015) The North Atlantic subpolar circulation in an eddy-resolving global ocean model. J Mar Syst 142:126-143. https://doi.org/10.1016/j.jmarsys.2014.10.007. https://www.scien cedirect.com/science/article/pii/S0924796314002437

Masson V, Moigne PL, Martin E, Faroux S, Alias A, Alkama R, Belamari S, Barbu A, Boone A, Bouyssel F, Brousseau P, Brun E, Calvet JC, Carrer D, Decharme B, Delire C, Donier S, Essaouini K, Gibelin AL, Giordani H, Habets F, Jidane M, Kerdraon G, Kourzeneva E, Lafaysse M, Lafont S, Lebeaupin Brossier C, Lemonsu A, Mahfouf JF, Marguinaud P, Mokhtari M, Morin S, Pigeon G, Salgado R, Seity Y, Taillefer F, Tanguy G, Tulet P, Vincendon B, Vionnet V, Voldoire A (2013) The SURFEXv7.2 land and ocean surface platform for coupled or offline simulation of earth surface variables and fluxes. Geosci Model Dev 6(4):929-960. https://doi.org/10.5194/gmd-6-929-2013. https:// www.geosci-model-dev.net/6/929/2013/gmd-6-929-2013.html

McGregor S, Timmermann A, Stuecker MF, England MH, Merrifield M, Jin FF, Chikamoto Y (2014) Recent Walker circulation strengthening and Pacific cooling amplified by Atlantic warming. Nature Climate Change 4(10):888-892, https://doi.org/10. 1038/nclimate2330, https://www.nature.com/articles/nclimate23 30, number: 10 Publisher: Nature Publishing Group

McGregor S, Stuecker MF, Kajtar JB, England MH, Collins M (2018) Model tropical Atlantic biases underpin diminished Pacific decadal variability. Nature Climate Change 8(6):493-498, https:// doi.org/10.1038/s41558-018-0163-4, https://www.nature.com/ articles/s41558-018-0163-4, number: 6 Publisher: Nature Publishing Group

Meehl GA, Hu A, Castruccio F, England MH, Bates SC, Danabasoglu G, McGregor S, Arblaster JM, Xie SP, Rosenbloom N (2021) Atlantic and Pacific tropics connected by mutually interactive decadal-timescale processes. Nat Geosci 14(1):36-42. https:// doi.org/10.1038/s41561-020-00669-x. https://www.nature.com/ articles/s41561-020-00669-x, number: 1 Publisher: Nature Publishing Group

Minobe S, Kuwano-Yoshida A, Komori N, Xie SP, Small RJ (2008) Influence of the Gulf Stream on the troposphere. Nature 452(7184):206-209. https://doi.org/10.1038/nature06690. https://www.nature.com/articles/nature06690, bandiera_abtest: a Cg_type: Nature Research Journals Number: 7184 Primary_ atype: Research Publisher: Nature Publishing Group

Mohino E, Janicot S, Bader J (2011) Sahel rainfall and decadal to multi-decadal sea surface temperature variability. Clim Dyn 37(3):419-440. https://doi.org/10.1007/s00382-010-0867-2
Monerie PA, Robson J, Dong B, Hodson DLR, Klingaman NP (2019) Effect of the Atlantic multidecadal variability on the global monsoon. Geophys Res Lett 46(3):1765-1775. https://doi.org/ 10.1029/2018GL080903

Monerie PA, Robson J, Dong B, Hodson D (2020) Role of the Atlantic multidecadal variability in modulating East Asian climate. Clim Dyn. https://doi.org/10.1007/s00382-020-05477-y

Montégut CdB, Madec G, Fischer AS, Lazar A, Iudicone D (2004) Mixed layer depth over the global ocean: an examination of profile data and a profile-based climatology. J Geophys Res Oceans 109(C12). https://doi.org/10.1029/2004JC002378

Morice CP, Kennedy JJ, Rayner NA, Jones PD (2012) Quantifying uncertainties in global and regional temperature change using an ensemble of observational estimates: the HadCRUT4 data set. J Geophys Res Atmos 117(D8). https://doi.org/10.1029/2011J D017187

Nigam S, Ruiz-Barradas A, Chafik L (2018) Gulf Stream Excursions and Sectional Detachments Generate the Decadal Pulses in the Atlantic Multidecadal Oscillation. J Clim 31(7):2853-2870. https://doi.org/10.1175/JCLI-D-17-0010.1. https://journals.amets oc.org/view/journals/clim/31/7/jcli-d-17-0010.1.xml, publisher: American Meteorological Society Section: Journal of Climate

Noilhan J, Planton S (1989) A Simple Parameterization of Land Surface Processes for Meteorological Models. Monthly Weather Rev 117(3):536-549. https://doi.org/10.1175/1520-0493(1989)117< 0536:ASPOLS>2.0.CO;2

Omrani NE, Keenlyside NS, Bader J, Manzini E (2014) Stratosphere key for wintertime atmospheric response to warm Atlantic decadal conditions. '//' 42(3-4):649-663. https://doi.org/10.1007/ s00382-013-1860-3

Omrani NE, Bader J, Keenlyside NS, Manzini E (2016) Tropospherestratosphere response to large-scale North Atlantic Ocean variability in an atmosphere/ocean coupled model. Clim Dyn 46(5):1397-1415. https://doi.org/10.1007/s00382-015-2654-6

Otterå OH, Bentsen M, Drange H, Suo L (2010) External forcing as a metronome for Atlantic multidecadal variability. Nat Geosci 3(10):688-694. https://doi.org/10.1038/ngeo955. https://www. nature.com/articles/ngeo955

O'Reilly CH, Woollings T, Zanna L (2017) The dynamical influence of the Atlantic multidecadal oscillation on continental climate. J Clim 30(18):7213-7230. https://doi.org/10.1175/ JCLI-D-16-0345.1

Parfitt R, Czaja A, Minobe S, Kuwano-Yoshida A (2016) The atmospheric frontal response to SST perturbations in the Gulf Stream region. Geophys Res Lett 43(5):2299-2306. https://doi.org/10. 1002/2016GL067723

Peings Y, Magnusdottir G (2014) Forcing of the wintertime atmospheric circulation by the multidecadal fluctuations of the North Atlantic ocean. Environ Res Lett 9(3):034018. https://doi.org/10. 1088/1748-9326/9/3/034018

Qasmi S, Cassou C, Boé J (2017) Teleconnection between Atlantic multidecadal variability and European temperature: diversity and evaluation of the coupled model intercomparison project phase 5 models. Geophys Res Lett 44(21):11,140-11,149. https://doi. org/10.1002/2017GL074886

Roberts CD, Senan R, Molteni F, Boussetta S, Mayer M, Keeley SPE (2018) Climate model configurations of the ECMWF Integrated Forecasting System (ECMWF-IFS cycle 43r1) for HighResMIP. Geosci Model Dev 11(9):3681-3712. https://doi.org/10.5194/ gmd-11-3681-2018

Rodríguez-Fonseca B, Polo I, García-Serrano J, Losada T, Mohino E, Mechoso CR, Kucharski F (2009) Are Atlantic Niños enhancing Pacific ENSO events in recent decades? Geophys Res Lett 36(20). https://doi.org/10.1029/2009GL040048

Ruggieri P, Bellucci A, Nicolí D, Athanasiadis PJ, Gualdi S, Cassou C, Castruccio F, Danabasoglu G, Davini P, Dunstone N, Eade 
R, Gastineau G, Harvey B, Hermanson L, Qasmi S, RuprichRobert Y, Sanchez-Gomez E, Smith D, Wild S, Zampieri M (2021) Atlantic Multidecadal Variability and North Atlantic Jet: A Multimodel View from the Decadal Climate Prediction Project. Journal of Climate 34(1):347-360, https://doi.org/10.1175/ JCLI-D-19-0981.1, https://journals.ametsoc.org/view/journals/ clim/34/1/JCLI-D-19-0981.1.xml, publisher: American Meteorological Society Section: Journal of Climate

Ruprich-Robert Y, Cassou C (2015) Combined influences of seasonal East Atlantic Pattern and North Atlantic Oscillation to excite Atlantic multidecadal variability in a climate model. Clim Dyn 44(1):229-253. https://doi.org/10.1007/s00382-014-2176-7

Ruprich-Robert Y, Msadek R, Castruccio F, Yeager S, Delworth T, Danabasoglu G (2017) Assessing the Climate Impacts of the Observed Atlantic Multidecadal Variability Using the GFDL CM2.1 and NCAR CESM1 Global Coupled Models. Journal of Climate 30(8):2785-2810, https://doi.org/10.1175/JCLI-D16-0127.1, https://journals.ametsoc.org/jcli/article/30/8/2785/ 95114/Assessing-the-Climate-Impacts-of-the-Observed, publisher: American Meteorological Society

Ruprich-Robert Y, Delworth T, Msadek R, Castruccio F, Yeager S, Danabasoglu G (2018) Impacts of the Atlantic Multidecadal Variability on North American Summer Climate and Heat Waves. Journal of Climate 31(9):3679-3700, https://doi.org/10. 1175/JCLI-D-17-0270.1, https://journals.ametsoc.org/jcli/artic le/31/9/3679/89307/Impacts-of-the-Atlantic-Multidecadal-Varia bility, publisher: American Meteorological Society

Ruprich-Robert Y, Moreno-Chamarro E, Levine X, Bellucci A, Cassou C, Castruccio F, Davini P, Eade R, Gastineau G, Hermanson L, Hodson D, Lohmann K, Lopez-Parages J, Monerie PA, Nicolì D, Qasmi S, Roberts CD, Sanchez-Gomez E, Danabasoglu G, Dunstone N, Martin-Rey M, Msadek R, Robson J, Smith D, Tourigny E (2021) Impacts of Atlantic multidecadal variability on the tropical Pacific: a multi-model study. npj Climate and Atmospheric Science 4(1):1-11, https://doi.org/10.1038/s41612-021-00188-5, https://www.nature.com/articles/s41612-021-00188-5, number: 1 Publisher: Nature Publishing Group

Salas Mélia D (2002) A global coupled sea ice-ocean model. Ocean Modelling 4(2):137-172, https://doi.org/10.1016/S14635003(01)00015-4, http://www.sciencedirect.com/science/artic le/pii/S1463500301000154

Sato M, Hansen JE, McCormick MP, Pollack JB (1993) Stratospheric aerosol optical depths, 1850-1990. J Geophys Res 98(D12):22987-22994. https://doi.org/10.1029/93jd02553

Scaife AA, Smith D (2018) A signal-to-noise paradox in climate science. npj Climate and Atmospheric Science 1(1), https://doi.org/ 10.1038/s41612-018-0038-4

Scaife AA, Arribas A, Blockley E, Brookshaw A, Clark RT, Dunstone N, Eade R, Fereday D, Folland CK, Gordon M, Hermanson L, Knight JR, Lea DJ, MacLachlan C, Maidens A, Martin M, Peterson AK, Smith D, Vellinga M, Wallace E, Waters J, Williams A (2014) Skillful long-range prediction of European and North American winters. Geophys Res Lett 41(7):2014GL0596372519. https://doi.org/10.1002/2014gl059637

Scaife AA, Comer RE, Dunstone NJ, Knight JR, Smith DM, MacLachlan C, Martin N, Peterson KA, Rowlands D, Carroll EB, Belcher S, Slingo J (2017) Tropical rainfall, Rossby waves and regional winter climate predictions. Q J R Meteorol Soc 143(702):1-11. https://doi.org/10.1002/qj.2910

Schiemann R, Demory ME, Shaffrey LC, Strachan J, Vidale PL, Mizielinski MS, Roberts MJ, Matsueda M, Wehner MF, Jung T (2017) The Resolution Sensitivity of Northern Hemisphere Blocking in Four 25-km Atmospheric Global Circulation Models. Journal of Climate 30(1):337-358, https://doi.org/10.1175/JCLI-D-160100.1, https://journals.ametsoc.org/view/journals/clim/30/1/ jcli-d-16-0100.1.xml, publisher: American Meteorological Society Section: Journal of Climate

Shapiro LJ, Goldenberg SB (1998) Atlantic Sea Surface Temperatures and Tropical Cyclone Formation. Journal of Climate 11(4):578 590. https://doi.org/10.1175/1520-0442(1998)011\%3C0578:ass tat\%3E2.0.co;2

Smith DM, Murphy JM (2007) An objective ocean temperature and salinity analysis using covariances from a global climate model. J Geophys Res 112(C2):C02022+. https://doi.org/10.1029/2005j c003172

Stevens B, Giorgetta M, Esch M, Mauritsen T, Crueger T, Rast S, Salzmann M, Schmidt H, Bader J, Block K, Brokopf R, Fast I, Kinne S, Kornblueh L, Lohmann U, Pincus R, Reichler T, Roeckner E (2013) Atmospheric component of the MPI-M Earth System Model: ECHAM6. Journal of Advances in Modeling Earth Systems 5(2):146-172. https://doi.org/10.1002/jame.20015

Storch Hv, Zwiers FW (1999) Statistical Analysis in Climate Research. Cambridge University Press, Cambridge, https://doi.org/10.1017/ CBO9780511612336, https://www.cambridge.org/core/books/ statistical-analysis-in-climate-research/9125090F106D2845485E 4BACD79B9695

Sun C, Li J, Zhao S (2015) Remote influence of Atlantic multidecadal variability on Siberian warm season precipitation. Scientific Reports 5(1):16853, https://doi.org/10.1038/srep16853, https://www.nature.com/articles/srep16853, bandiera_abtest: a Cc_license_type: cc_by Cg_type: Nature Research Journals Number: 1 Primary_atype: Research Publisher: Nature Publishing Group Subject_term: Atmospheric dynamics;Climate change;Hydrology;Planetary science Subject_term_id: atmospheric-dynamics;climate-change; hydrology;planetary-science

Sutton RT, Dong B (2012) Atlantic Ocean influence on a shift in European climate in the 1990s. Nature Geoscience 5(11):788-792, https://doi.org/10.1038/ngeo1595, https://www.nature.com/artic les/ngeo1595

Sutton RT, Hodson DLR (2005) Atlantic Ocean Forcing of North American and European Summer Climate. Science 309(5731):115-118. https://doi.org/10.1126/science.1109496

Sutton RT, Hodson DLR (2007) Climate Response to Basin-Scale Warming and Cooling of the North Atlantic Ocean. J Clim 20(5):891-907. https://doi.org/10.1175/jcli4038.1

Swingedouw D, Ortega P, Mignot J, Guilyardi E, Masson-Delmotte V, Butler PG, Khodri M, Séférian R (2015) Bidecadal North Atlantic ocean circulation variability controlled by timing of volcanic eruptions. Nature Communications 6(1):6545, https://doi.org/ 10.1038/ncomms7545, https://www.nature.com/articles/ncomm s7545, bandiera_abtest: a Cg_type: Nature Research Journals Number: 1 Primary_atype: Research Publisher: Nature Publishing Group Subject_term: Atmospheric science;Climate-change impacts;Palaeoceanography;Volcanology Subject_term_id: atmospheric-science;climate-change-impacts;palaeoceanograp hy; volcanology

Ting M, Kushnir Y, Seager R, Li C (2011) Robust features of Atlantic multi-decadal variability and its climate impacts. Geophys Res Lett 38(17):L17705+. https://doi.org/10.1029/2011g1048712

Undorf S, Bollasina MA, Booth BBB, Hegerl GC (2018) Contrasting the Effects of the 1850-1975 Increase in Sulphate Aerosols from North America and Europe on the Atlantic in the CESM. Geophys Res Lett 45(21):11,930-11,940. https://doi.org/10.1029/ 2018GL079970

Uvo CB, Repelli CA, Zebiak SE, Kushnir Y (1998) The Relationships between Tropical Pacific and Atlantic SST and Northeast Brazil Monthly Precipitation. Journal of Climate 11(4):551-562. https://doi.org/10.1175/1520-0442(1998)011\%3C0551:trbtpa\% 3E2.0.co;2

Valcke S (2013) The OASIS3 coupler: a European climate modelling community software. Geoscientific Model Development 
6(2):373-388, https://doi.org/10.5194/gmd-6-373-2013, https:// www.geosci-model-dev.net/6/373/2013/

Vancoppenolle M, Bouillon S, Fichefet T, Goosse H, Arzel O, Morales Maqueda MA, Madec G (2012) LIM The Louvainla-Neuve sea Ice Model. http://www.climate.be/users/lecomte/ LIM3_users_guide_2012.pdf

Vellinga M, Wood RA (2002) Global Climatic Impacts of a Collapse of the Atlantic Thermohaline Circulation. Clim Change 54(3):251267. https://doi.org/10.1023/a:1016168827653

Vigaud N, Ting M, Lee DE, Barnston AG, Kushnir Y (2018) Multiscale Variability in North American Summer Maximum Temperatures and Modulations from the North Atlantic Simulated by an AGCM. Journal of Climate 31(7):2549-2562, https://doi. org/10.1175/JCLI-D-17-0392.1, https://journals.ametsoc.org/jcli/ article/31/7/2549/89965/Multiscale-Variability-in-North-Ameri can-Summer, publisher: American Meteorological Society

Voldoire A, Saint-Martin D, Sénési S, Decharme B, Alias A, Chevallier M, Colin J, Guérémy JF, Michou M, Moine MP, Nabat P, Roehrig R, Mélia DSy, Séférian R, Valcke S, Beau I, Belamari S, Berthet S, Cassou C, Cattiaux J, Deshayes J, Douville H, Ethé C, Franchistéguy L, Geoffroy O, Lévy C, Madec G, Meurdesoif Y, Msadek R, Ribes A, Sanchez-Gomez E, Terray L, Waldman R, (2019) Evaluation of CMIP6 DECK Experiments With CNRM-CM6-1. Journal of Advances in Modeling Earth Systems 11(7):2177-2213. https://doi.org/10.1029/2019MS001683

Wallace JM, Gutzler DS (1981) Teleconnections in the Geopotential Height Field during the Northern Hemisphere Winter. Monthly Weather Review 109(4):784-812, https://doi.org/10.1175/15200493(1981) 109<0784:TITGHF>2.0.CO;2, https://journals. ametsoc.org/view/journals/mwre/109/4/1520-0493_1981_109_ 0784_titghf_2_0_co_2.xml, publisher: American Meteorological Society Section: Monthly Weather Review

Walters D, Boutle I, Brooks M, Melvin T, Stratton R, Vosper S, Wells H, Williams K, Wood N, Allen T, Bushell A, Copsey D, Earnshaw P, Edwards J, Gross M, Hardiman S, Harris C, Heming J, Klingaman N, Levine R, Manners J, Martin G, Milton S, Mittermaier M, Morcrette C, Riddick T, Roberts M, Sanchez C, Selwood P, Stirling A, Smith C, Suri D, Tennant W, Vidale PL, Wilkinson J, Willett M, Woolnough S, Xavier P (2017) The Met Office Unified Model Global Atmosphere 6.0/6.1 and JULES Global Land 6.0/6.1 configurations. Geoscientific Model Development 10(4):1487-1520, https://doi.org/10.5194/gmd-10-14872017, https://www.geosci-model-dev.net/10/1487/2017/

Wang C (2018) A review of ENSO theories. Natl Sci Rev 5(6):813825. https://doi.org/10.1093/nsr/nwy104
Watanabe M, Tatebe H (2019) Reconciling roles of sulphate aerosol forcing and internal variability in Atlantic multidecadal climate changes. Clim Dyn 53(7):4651-4665. https://doi.org/10.1007/ s00382-019-04811-3

Wilks DS (2019) Chapter 5-Frequentist Statistical Inference. In: Wilks DS (ed) Statistical Methods in the Atmospheric Sciences (Fourth Edition), Elsevier, pp 143-207, https://doi.org/10.1016/ B978-0-12-815823-4.00005-5, https://www.sciencedirect.com/ science/article/pii/B9780128158234000055

Yip S, Ferro CAT, Stephenson DB, Hawkins E (2011) A Simple, Coherent Framework for Partitioning Uncertainty in Climate Predictions. J Clim 24(17):4634-4643. https://doi.org/10.1175/ 2011JCLI4085.1

Zhang L, Delworth TL (2015) Analysis of the Characteristics and Mechanisms of the Pacific Decadal Oscillation in a Suite of Coupled Models from the Geophysical Fluid Dynamics Laboratory. Journal of Climate 28(19):7678-7701, https://doi.org/10.1175/ JCLI-D-14-00647.1, https://journals.ametsoc.org/view/journals/ clim/28/19/jcli-d-14-00647.1.xml, publisher: American Meteorological Society Section: Journal of Climate

Zhang R, Delworth TL (2005) Simulated Tropical Response to a Substantial Weakening of the Atlantic Thermohaline Circulation. J Clim 18(12):1853-1860. https://doi.org/10.1175/jcli3460.1

Zhang R, Delworth TL (2006) Impact of Atlantic multidecadal oscillations on India/Sahel rainfall and Atlantic hurricanes. Geophysical Research Letters 33(17), https://doi.org/10.1029/2006GL026267

Zhang Z, Chan JCL, Ding Y (2004) Characteristics, evolution and mechanisms of the summer monsoon onset over Southeast Asia. Int J Climatol 24(12):1461-1482. https://doi.org/10.1002/joc. 1082

Zhou J, Lau KM (2001) Principal modes of interannual and decadal variability of summer rainfall over South America. Int J Climatol 21(13):1623-1644. https://doi.org/10.1002/joc.700

Zhou T, Yu R, Zhang J, Drange H, Cassou C, Deser C, Hodson DL, Sanchez-Gomez E, Li J, Keenlyside N, Xin X, Okumura Y (2009) Why the Western Pacific Subtropical High Has Extended Westward since the Late 1970s. J Clim 22(8):2199-2215. https:// doi.org/10.1175/2008jcli2527.1

Zwiers FW (1996) Interannual variability and predictability in an ensemble of AMIP climate simulations conducted with the CCC GCM2. Clim Dyn 12(12):825-847. https://doi.org/10.1007/ s003820050146

Publisher's Note Springer Nature remains neutral with regard to jurisdictional claims in published maps and institutional affiliations. 